\title{
Preconcentration and sensitive determination of the anti-inflammatory drug diclofenac on a paper-based electroanalytical platform
}

\author{
E. Costa-Rama ${ }^{a}$, H.P.A. Nouws ${ }^{\mathrm{a}}$, C. Delerue-Matos ${ }^{\mathrm{a}}$, M.C. Blanco-López ${ }^{\mathrm{b}}$, M. T. Fernández-Abedul ${ }^{\mathrm{b} *}$ \\ ${ }^{a}$ REQUIMTE/LAQV, Instituto Superior de Engenharia do Porto, Instituto Politécnico do Porto, Dr. António \\ Bernardino de Almeida 431, 4200-072 Porto, Portugal \\ bDepartamento de Química Física y Analítica, Universidad de Oviedo, 33006 Oviedo, Spain \\ *e-mails: mtfernandeza@uniovi.es; estefaniarama@graq.isep.ipp.pt \\ *Tel.: +34 985102968
}

\begin{abstract}
This work describes the development of a paper-based platform for highly sensitive detection of diclofenac. The quantification of this anti-inflammatory drug is of importance in clinical (e.g. quality- and therapeutic control) and environmental (e.g. emerging contaminant determination) areas. The easy-to-handle platform here described consists of a carbon-ink paper-based working electrode and two metallic wires, provided by a gold-plated standard connector, as reference and counter electrodes. The porous paper matrix enables the preconcentration of the sample, decoupling sample and detection solutions. Thus, relatively large sample volumes can be used, which significantly improves the sensitivity of the method. A wide dynamic range of four orders of magnitude, between 0.10 and $100 \mu \mathrm{M}$, was obtained for diclofenac determination. Due to the predominance of adsorption at the lowest concentrations, there were two linear concentration ranges: one comprised between 0.10 and $5.0 \mu \mathrm{M}$ (with a slope

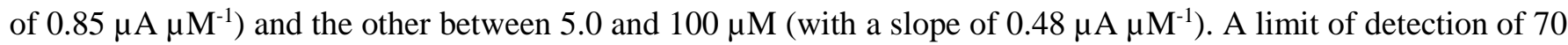
$\mathrm{nM}$ was achieved with this simple device. The platform provided accurate results with an RSD of $c a .5 \%$. It was applied for diclofenac quantification in spiked tap water samples. The versatility of this design enabled the fabrication of a multiplexed platform containing eight electrochemical cells that work independently. The low cost, small size and simplicity of the device allow on-site analysis, which is very useful for environmental monitoring.
\end{abstract}

\section{Keywords}

Paper-based electroanalysis, electroanalytical platforms, multiplexing, low-cost analysis, diclofenac, antiinflammatory drugs.

\section{Introduction}

Diclofenac (DCF), or 2-(2-((2,6-dichlorophenyl) amino) phenyl) acetic acid, is a common non-steroidal antiinflammatory drug (NSAID) with analgesic and antipyretic properties [1]. Sold under the brand name Voltaren® among others, DCF is frequently prescribed for rheumatic complaints, acute joint inflammation and mild to moderate pain [1,2]. Its analysis is of interest in two main fields: i) quality control of pharmaceutical drugs, an important issue due to the reinforcement of regulatory controls on the pharmaceutical industry, and ii) therapeutic control of the drugs administered. Therefore, the samples that are commonly analyzed are pharmaceuticals or biological fluids [3-7]. Due to its wide use, DCF residues have often been detected in freshwater environments [8-10]. Thus, DCF is considered an emerging contaminant (EC) as a consequence of its occurrence in surface waters and its potential toxicity towards aquatic organisms [11,12]. ECs comprise a wide assortment of substances (e.g. endocrine disruptors, drugs of abuse, pharmaceuticals and personal care products) characterized by an extensive distribution in the environment, due to their massive everyday use and persistence $[13,14]$. One of the main reasons for their broad distribution is related to the inability of conventional wastewater treatment plants to remove them completely $[11,15]$. ECs, commonly present at trace concentrations, have been associated with negative effects on human and animal health (e.g. nervous system damage, toxicity or disruption of the immune system) [15]. Several studies have described harmful effects to different organisms when exposed to environmental levels of DCF $[16,17]$. These may vary from a few ng $\mathrm{L}^{-1}$ to tens of $\mu \mathrm{g} \mathrm{L}^{-1}$ $[9,11,18]$ in waste and environmental waters. Taking the aspects mentioned above into account, the quantification 
of DCF in environmental waters is of great importance, not only to improve the current state of knowledge regarding its pathways, fate and effects in the environment, but also to determine the efficiency of wastewater treatment plants.

In this context, the development of methods for the analysis of DCF is clearly a challenge. Therefore, several approaches have been employed, such as absorption and fluorescence spectrophotometry [19], capillary electrophoresis (CE) $[3,20]$ or liquid chromatography-mass spectrometry (LC-MS) [5,8]. Since DCF can be electrochemically oxidized, it can also be determined by electrochemical techniques [6,7,21-36]. Compared with the previously referred methods, electrochemical methodologies are an interesting alternative because of their: i) low cost, ii) rapid response, iii) potential portability and iv) simple fabrication and easy handling. Moreover, the colour or turbidity of the sample is not an inconvenience when these methods are employed, so the sample treatment is often simple [37-39]. Several publications describe electrochemical sensors for DCF detection, that are either based on potentiometry [29,30], electrochemical impedance spectroscopy (EIS) [31] or amperometry [32-35]. Biological reagents such as antibodies [6], biologically-derived materials such as aptamers $[31,33,36]$, or molecularly-imprinted polymers (MIPs) [21,22] have been used in the construction of electroanalytical platforms for DCF detection with the aim of improving selectivity. Similarly, modifications of electrodes with ionic liquids [7,23,24,35] and/or different nanomaterials such as metallic nanoparticles [25,26], carbon nanotubes $[7,23,24,34,35]$ or graphene [27,32] have been employed for electrooxidation-based DCF quantification. Electroanalytical methods have been also used in combination with MIP-based solid phase extraction [28].

In the last years, the need for decentralized and low cost analysis, either in clinical (point-of-care tests), environmental (field analysis) or other areas (on-site determinations), has raised the interest in the use of paper as substrate for the development of analytical platforms [40-44]. This is mainly due to its very low cost, lightness, abundance and widespread availability, biodegradability, hydrophilicity and porosity (that allow the passive flow of liquids via capillary forces) [44,45]. Electrochemical detection fits perfectly with paper-based analytical devices, especially because of its potential for miniaturization and portability [46]. Thus, paper-based electroanalytical devices have proven to be powerful analytical platforms for clinical applications $[47,48]$ as well as for environmental $[40,42]$ or food analysis [49-51]. However, to the best of our knowledge, the development of paperbased analytical devices for DCF detection has not been reported.
In the present work, we add one more function to a very simple and easy-to-use paper-based electroanalytical platform [52]. In this way, we use it not only for the electrochemical detection of DCF, but also for its preconcentration. Thus, the analytical methodology becomes extremely sensitive thanks to the multifunctionality of the paper-based platform. The device fits into the concept of lab-on-paper since we added one more step, integrating preconcentration and measurement in the same electrochemical cell. This consisted of a paperbased carbon-ink working electrode (WE), which did not need any stencil or screen for fabrication, and external reference (RE) and counter (CE) wire electrodes provided by a standard electronic element widely available on the market. This platform is very appropriate for the analysis of DCF in environmental samples since it is: i) low cost, ii) simple (easy-to-construct and to-use), iii) portable (allowing on-site measurements) and iv) green (since it generates very low amounts of waste). Nevertheless, one of the main challenges in the analysis of emergent contaminants is the requirement of ultrasensitive methodologies since they are often present at trace levels in environmental waters. Therefore, the possibility of DCF preconcentration on paper-based analytical devices was evaluated for the first time. Paper is suitable for storage of different materials, including: i) bioreagents, ii) conductive materials and iii) samples. These can then be easily stored, since the high area-to-volume ratio favours solvent evaporation and compounds can be adsorbed or trapped on the cellulose fibres and pores. Thus, in this work we have taken advantage of the paper-based WE for preconcentrating DCF. In this way, paper is employed as i) the platform for fabricating the carbon ink-based working electrode (by deposition of the ink), ii) the substrate for sample preconcentration (by solvent evaporation) and iii) the container to place the RE and CE as well as to deposit the supporting electrolyte. On the other hand, the multiplexing of analysis is becoming of paramount interest because of the increasing demand for more information in a shorter time. Spatial separation of complete electrochemical cells in the same platform allows performing simultaneous measurements when a multipotentiostat is employed. In this work, the versatility of the design was demonstrated by constructing an 8electrochemical-cell platform for multiplexed measurements. The analysis time did not increase because the wax printing and diffusion, employed for delimiting working areas, as well as the deposition of the ink were carried out simultaneously for all the cells.

\section{Materials and Methods}

\subsection{Chemicals, materials and instrumentation}


Diclofenac disodium salt was purchased from SigmaAldrich, N,N-dimethylformamide (DMF) from VWR International and the carbon paste from Gwent Group. Carbon nanofibers (CNFs) were provided by Grupo Antolin and the dispersion $\left(0.05 \mathrm{mg} \mathrm{mL}^{-1}\right.$ in DMF) of carboxylated multiwalled carbon nanotubes (MWCNTs) was purchased from DropSens. Water used throughout this work was obtained from a Millipore Direct-Q $\mathrm{Q}^{\mathrm{TM}} 5$ purification system and all chemicals employed were of analytical reagent grade.

A 50-mM DCF solution was prepared daily in ultrapure water. Working solutions were prepared either in water or in $0.1 \mathrm{M}$ phosphate buffer (PB) solution $\mathrm{pH} 7.0$, depending on the assay. For pH studies, Britton-Robinson buffer solutions of $\mathrm{pH}$ values comprised between 5 and 10 were employed. This universal buffer consists of a mixture of $0.04 \mathrm{M} \mathrm{H}_{3} \mathrm{BO}_{3}, 0.04 \mathrm{M} \mathrm{H}_{3} \mathrm{PO}_{4}$ and $0.04 \mathrm{M} \mathrm{CH}_{3} \mathrm{COOH}$ that has been taken to the desired $\mathrm{pH}$ with $0.2 \mathrm{M} \mathrm{NaOH}$.

Whatman $^{\mathrm{TM}}$ chromatographic paper grade 1 and a wax printer ColorQube 8570 (XEROX) were employed for the fabrication of the paper-based electrodes. Gold-plated connector headers were purchased from Digikey and an edge connector (ref. DRP-DSC) was purchased from DropSens.

For voltammetric measurements performed with the single working electrode platform, a Metrohm-Autolab PGSTAT12 potentiostat controlled by Nova 2.1.2 software was employed. Measurements with the multiplexed platform were performed using a $\mu$ Stat8000 potentiostat (DropSens) controlled by DropView 84002.0 software. All measurements were carried out at room temperature.

\subsection{Fabrication of the paper-based electrochemical} cell.

The single electrochemical cell was fabricated following a procedure recently described [52]. In summary, the electrochemical cell consisted of a paper-based working electrode (WE) combined with counter (CE) and pseudoreference (RE) electrodes based on metallic wires (Fig. 1, left). The WE was prepared by depositing $2 \mu \mathrm{L}$ of carbon ink $(40 \%$ of carbon paste in DMF; sonicated for 1 h) on a wax-printed paper area, which was left to dry for $12 \mathrm{~h}$. To define the area of the WE, first a circular pattern with a diameter of $4 \mathrm{~mm}$ - was wax printed on the chromatographic paper and then it was diffused at $100^{\circ} \mathrm{C}$ on a heating plate for $1 \mathrm{~min}$ (see Fig. S1). The RE and CE were the pins of a commercial connector (previously cut to take a three-pin element). The connector consisted of three pins that crossed a black plastic piece. The pins were goldplated on one side (Fig. 1A). These plated pins were employed as electrodes (CE and RE) and also as connection for the carbon ink of the WE. The pins at the other side of the plastic piece (non-plated) were employed as an easy connection that fitted the commercial interface that finally connected to the potentiostat (Fig. 1D).

The RE and CE were placed in a different plane from the pin that connects the WE and were bent to place them within the WE area. In this way, a clip was formed and the paper-based WE could be easily inserted (see Fig. 1) without the need of adhesives, cables or similar elements. The working solution was deposited on the opposite side of the ink, and then, it contacted the WE (through the paper) as well as the $\mathrm{RE}$ and $\mathrm{CE}$, while the wireconnection for the WE was not in contact with the solution.

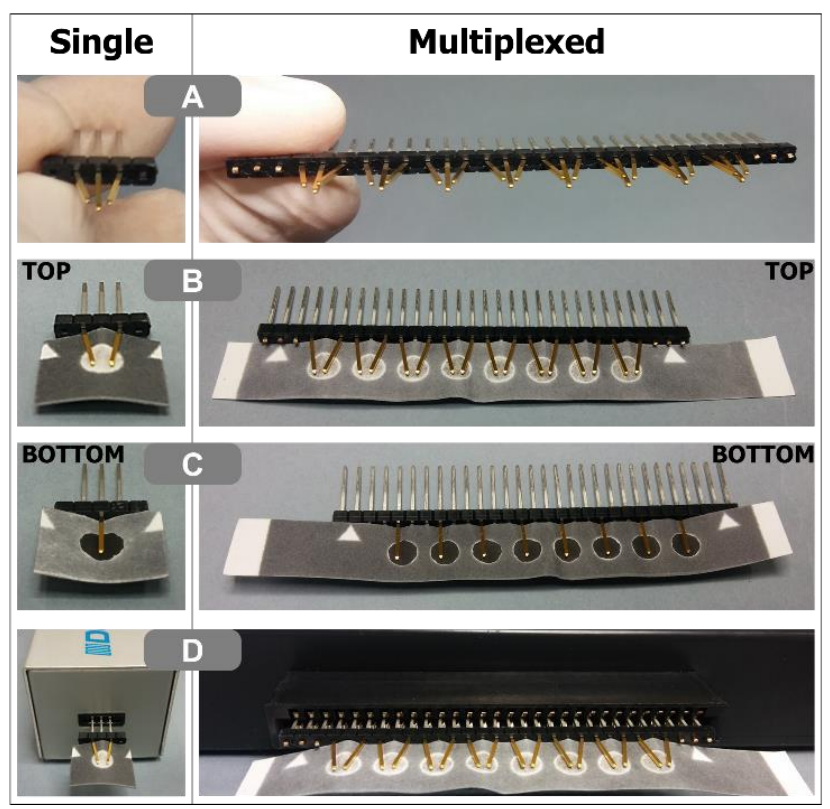

Fig. 1. Photographs of the: A) gold-plated connector headers after being bent to obtain clips where the paper-based working electrodes are inserted; B) top and C) bottom views of the complete electrochemical cells; D) platforms inserted in a commercial interface to connect the electrodes to the potentiostat, for the single (left) and multiplexed (right) paper-based electrochemical devices.

For the construction of the multiplexed paper-based platform (Fig. 1, right), the procedure was the same as for the single-WE platform. However, in this case the wax design was different (Fig. S1A). The diameter of the circular pattern remained the same $(4 \mathrm{~mm})$ but 8 circles were included on the same strip of paper. A gold-plated commercial connector header was also needed; nevertheless, in this case, the number of pins required was 24 instead of 3 . The connector header we used was a rack of 36 pins that can be cut into individual units. Thus, we took 24-pins to fabricate 8 electrochemical cells, but the device could be customized to include the desired number of electrochemical cells. An 8-channel micropipette was employed and simultaneous measurements were recorded using a multipotentiostat. 


\subsection{Preconcentration procedure}

For preconcentrating DCF on the paper-based WE, a drop of DCF solution (in water) was deposited onto the WE (on the opposite side of the ink) and left to dry at room temperature or in an oven. The drying time depends on the volume of the drop and the temperature (see Section 3.2).

\subsection{Modification with carbon nanomaterials.}

The modification of the paper-based WE with functionalized MWCNTs was performed by depositing 2 $\mu \mathrm{L}$ of a MWCNTs dispersion $\left(0.01\right.$ or $\left.0.02 \mathrm{mg} \mathrm{mL}^{-1}\right)$ in DMF on the WE, on the opposite side of the ink. For the modification with CNFs, a dispersion $\left(0.1\right.$ or $\left.0.2 \mathrm{mg} \mathrm{mL}^{-1}\right)$ in water was prepared. Then, a $5-\mu \mathrm{L}$ drop of this dispersion was deposited on the WE on the opposite side of the ink. In both cases, the dispersion of the carbon nanomaterial is left to dry overnight.

\subsection{Electrochemical measurements.}

Cyclic, linear sweep and differential pulse voltammograms (CVs, LSVs and DPVs, respectively) were recorded after depositing a $10-\mu \mathrm{L}$ drop of the corresponding solution on the paper-based platform (on the opposite side of the ink). CVs were recorded between -0.2 and $+1.2 \mathrm{~V}$ at $50 \mathrm{mV} \mathrm{s}^{-1}$. For LSV, the potential was scanned between +0.2 and +0.8 $\mathrm{V}$, at 50 or $100 \mathrm{mV} \mathrm{s}^{-1}$ depending on the assay. DPVs were obtained between +0.2 and $+0.8 \mathrm{~V}$ employing a pulse amplitude of $50 \mathrm{mV}$, a pulse width of $80 \mathrm{~ms}$, a pulse repetition time of $8 \mathrm{~s}$ and a scan rate of $6.25 \mathrm{mV} \mathrm{s}^{-1}$.

\section{Results and discussion}

To study the electrochemical behaviour of DCF on paperbased electrodes, $\mathrm{CV}$ was performed using $10 \mu \mathrm{L}$ of a 5 $\mathrm{mM}$ DCF solution (in 0.1 M PB pH 7.0). DCF (Fig. S2) is a benzeneacetic acid derivative with a pKa of 4.15 [1,53]. Thus, depending on the $\mathrm{pH}$, the predominant species is neutral or anionic [53]. Therefore, at the $\mathrm{pH}$ employed in this work (7.0), the anionic DCF species predominates. Several works discuss the possible mechanism of the electrooxidation of DCF at this $\mathrm{pH}$ on different carbon electrodes, such as glassy carbon [35], carbon ceramic [23], carbon paste [7,53] and edge plane pyrolytic graphite [54], suggesting mechanisms involving either one or two electrons. As shown in Fig. 2A, in the first scan, two anodic peaks were observed: the first (peak I), at $\approx+0.5 \mathrm{~V}$, was well-defined and had a peak current intensity of 75.3 $\mu \mathrm{A}$; the second (peak II) appeared at $\approx+0.9 \mathrm{~V}$ with a lower peak current intensity $(15.7 \mu \mathrm{A})$. A second scan resulted in an important suppression of the current of these processes, appearing the second one only at high concentrations. A cathodic peak appeared in the reverse sweep (peak III at $\approx$
$+0.25 \mathrm{~V}$ ) and, in the second scan, an additional oxidation peak (peak IV at $\approx+0.27 \mathrm{~V}$ ) was observed. This behaviour is in accordance with those reported for other modified/unmodified carbon electrodes $[21,23]$. Hence, in carbon ceramic electrodes either bare or modified with carbon nanotubes, DCF was irreversibly oxidized in BR buffer $\mathrm{pH} 7$ at $+0.502 \mathrm{~V}$ ( $v s$. saturated calomel electrode, potential window: -0.4 to $+0.7 \mathrm{~V}$ ) [23]. At the reverse sweep, a cathodic peak was noticed at $+0.193 \mathrm{~V}$, which formed a couple with an anodic peak $(+0.272 \mathrm{~V})$. On glassy carbon electrodes [21], (0.1 M PB pH 7) a welldefined anodic peak is observed at $+0.657 \mathrm{~V}$ (vs. $\mathrm{Ag} / \mathrm{AgCl}$, potential window: -0.2 to $+1.0 \mathrm{~V}$ ). Although a clear second anodic process at higher potentials is not observed, the intensity of the current does not decay The reduction process in the reverse scan indicated that some oxidation product was electrochemically active. Similarly to what was commented previously, a new oxidation process is also observed, in this case at $\approx+0.474 \mathrm{~V}$. Since the first anodic peak (I) had the highest current intensity and was the one with better definition, it was chosen as analytical signal for DCF quantification. The effect of $\mathrm{pH}$ on the current intensity of this peak was assessed performing linear sweep voltammetry in $50-\mu \mathrm{M}$ DCF solutions prepared in Britton-Robinson buffer solutions with $\mathrm{pH}$ values comprised between 5 and 10 (Fig. S3) and a maximum was observed between $\mathrm{pH} 6$ and 8. Thus, $\mathrm{pH} 7$ was chosen for analytical purposes since a higher peak current intensity was obtained and this $\mathrm{pH}$ value does not degrade the paper substrate. To maintain this $\mathrm{pH}$, a $0.1 \mathrm{M}$ phosphate buffer, reported in the bibliography for glassy carbon electrode [21] is employed for the remainder of the work. A calibration curve was obtained recording LSVs in $10 \mu \mathrm{L}$ of DCF solutions of different concentrations (Fig. S4). A linear relationship was found between 75 and 2500 $\mu \mathrm{M}$ according to the equation $i_{p}(\mu \mathrm{A})=0.013[\mathrm{DCF}](\mu \mathrm{M})$ $+0.868, \mathrm{R}^{2}=0.998$. The limit of detection (LOD), calculated as three times the standard deviation of the intercept divided by the slope, was $55 \mu \mathrm{M}$.

\subsection{Preconcentration and improvement of the analytical signal.}

With the aim of increasing the sensitivity of the methodology, a preconcentration step was carried out by taking advantage of the porous matrix of the paper. For this purpose, $10-\mu \mathrm{L}$ drops of a $100-\mu \mathrm{M}$ DCF solution (in water) were deposited on the surface of different WEs (on the opposite side of the ink) and left to dry at room temperature. Then, a CV was recorded after deposition of $10 \mu \mathrm{L}$ of $0.1 \mathrm{M}$ PB pH 7.0. In Fig. 2B, the results are depicted and compared with a $\mathrm{CV}$ performed in $10 \mu \mathrm{L}$ of a $100-\mu \mathrm{M}$ DCF solution (in 0.1 M PB pH 7.0) without the preconcentration step. In this case, only the first anodic peak appeared (the DCF concentration was much lower 
than in Fig. 2A). However, when DCF was preconcentrated on the paper-based electrode, the second anodic peak appeared and the current intensity of the first peak showed a huge increase. For this peak (peak I), the current intensity increased from $2.3 \mu \mathrm{A}$ (measuring in 10 $\mu \mathrm{L}$ of a $100-\mu \mathrm{M}$ DCF solution) to $7.4 \mu \mathrm{A}$ (evaporating 10 $\mu \mathrm{L}$ of a $100-\mu \mathrm{M}$ DCF solution and measuring in $10 \mu \mathrm{L}$ of the buffer solution) (Fig. 2B). Hence, a ca. 3-fold signal increase was achieved for the same concentration when the $\mathrm{CV}$ was performed after the preconcentration step. Since the initial volume was $10 \mu \mathrm{L}$ and the measurement was also made in $10 \mu \mathrm{L}$, there was no any preconcentration due to a change in volume. Therefore, the increase in the peak current intensity was probably due to the effect of solvent evaporation, which approached DCF molecules to the electrode surface, making the mass transport more efficient. It has to be also noted a slight shift of the oxidation peak to an overpotential lower than the one obtained without preconcentration (from $\approx+0.50$ to $\approx$ $+0.43 \mathrm{~V}$ ). It has been reported a shift to lower potentials in the oxidation peak of dopamine and nicotine when the electrode (glassy carbon in the case of dopamine [55] and basal plane pyrolytic graphite electrode for nicotine [56]) is modified with a carbon-nanotube layer When instead of flat electrodes, porous conductive layers are involved, the electrode can be modelled as a regular array of vertically aligned cylinders protruding out from the electrode surface. Then, at low cylinder separation, the peak occurs at lower overpotential than at a planar macroelectrode due to increasing extent of "thin layer" diffusion, which quickly consumes species from the small volume of solution between the cylinders [57]. In our case, paper is made of a network of cellulose fibres with pores and channels different in size. Then, deposition of carbon ink at the bottom can generate a great number of pillars and pores with different sizes and geometries. Apart from this, evaporation of the solvent will force the "load" of the proximity of the porous conductive layer with a higher amount of DCF molecules. Although some molecules could be retained in the non-conductive part of the paper, an increase would be produced close to the electrode surface, located at the bottom.
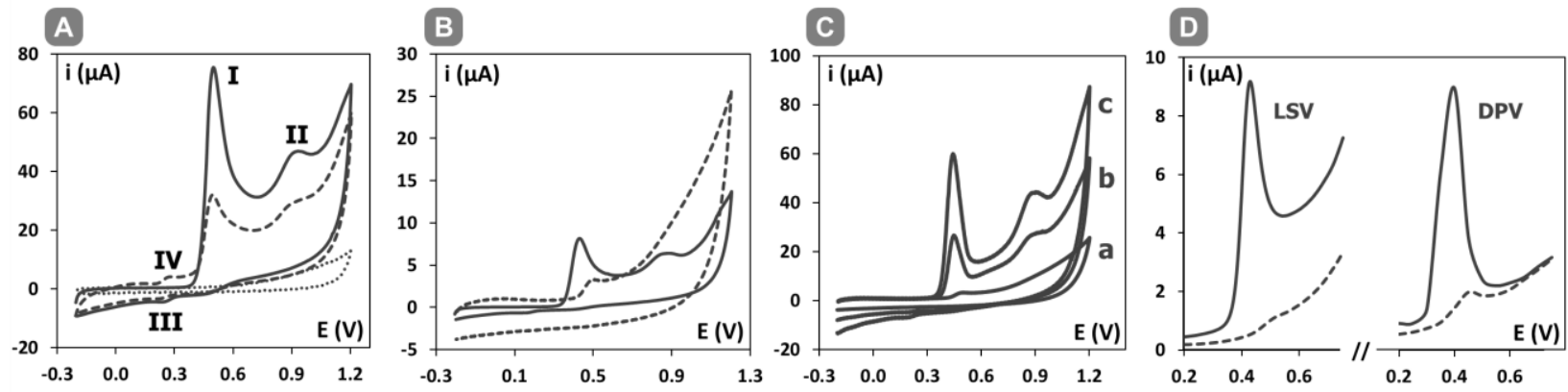

Fig. 2. (A) CVs recorded in $10 \mu \mathrm{L}$ of a 5-mM DCF solution in $0.1 \mathrm{M} \mathrm{PB} \mathrm{pH} 7.0$ (first scan, solid line; second scan, dashed line). The dotted line corresponds to the supporting electrolyte (0.1 M PB pH 7.0). (B) CVs recorded in $10 \mu \mathrm{L}$ of a $100-\mu \mathrm{M}$ DCF solution in $0.1 \mathrm{M}$ PB pH 7.0 (dashed line) and in $10 \mu \mathrm{L}$ of $0.1 \mathrm{M} \mathrm{PB} \mathrm{pH} 7.0$ after preconcentration of $10 \mu \mathrm{L}$ of a $100-\mu \mathrm{M}$ DCF solution in water (solid line). (C) CVs recorded in $10 \mu \mathrm{L}$ of (a) a 100- $\mu \mathrm{M}$ DCF solution in $0.1 \mathrm{M} \mathrm{PB} \mathrm{pH} 7.0$, and in $10 \mu \mathrm{L}$ of $0.1 \mathrm{M} \mathrm{PB} \mathrm{pH} 7.0$ after preconcentration of $40 \mu \mathrm{L}$ of: (b) $50-\mu \mathrm{M}$ and (c) $100-\mu \mathrm{M}$ DCF solutions in water. (D) LSVs and DPVs performed in $10 \mu \mathrm{L}$ of a $20-\mu \mathrm{M}$ DCF solution in $0.1 \mathrm{M}$ PB pH 7.0 (dashed line) and in $10 \mu \mathrm{L}$ of $0.1 \mathrm{M} \mathrm{PB} \mathrm{pH} 7.0$ after preconcentration of $40 \mu \mathrm{L}$ of a $20-\mu \mathrm{M}$ DCF solution in water (solid lines). Scan rate for CV and LSV: $50 \mathrm{mV} \mathrm{s}^{-1}$. DPV conditions: $50-\mathrm{mV}$ pulse amplitude, $80-\mathrm{ms}$ pulse width, 8-s pulse repetition time and $6.25-\mathrm{mV} \mathrm{s}^{-1}$ scan rate.

When higher volumes of DCF solution were used in the preconcentration step, the peak current intensities increased even further. Thus, $40-\mu \mathrm{L}$ drops of $50 \mu \mathrm{M}$ and $100 \mu \mathrm{M}$ DCF solutions were deposited and evaporated on different WEs. Then, CVs were recorded in $10 \mu \mathrm{L}$ of 0.1 M PB pH 7.0 (Fig. 2C) obtaining much higher peak current intensities. For peak I, in Fig. 2C, the current intensity increased from $2.3 \mu \mathrm{A}$ for $\mathrm{CV}$ " $\mathrm{a}$ " (10 $\mu \mathrm{L}$ of a $100 \mu \mathrm{M}$ DCF solution) to $58.8 \mu \mathrm{A}$ for $\mathrm{CV}$ "c" (recorded after preconcentrating $40 \mu \mathrm{L}$ of a $100 \mu \mathrm{M}$ DCF solution), thus resulting in a 25 -fold increase of the signal. The volume ratio (initial to final volume ratio) is 4 , thus the concentration increased from 100 to $400 \mu \mathrm{M}$. In this case, the increase in the current intensity was due to both effects, the closeness of the molecules to the electrode surface and the increase of the final concentration. Additionally, even in the case of lower concentrations (preconcentration of $40 \mu \mathrm{L}$ of a $50-\mu \mathrm{M}$ DCF solution) the signal increased to $25.8 \mu \mathrm{A}$, more than 10 fold for half the concentration (CV "b" in Fig. 2C). Therefore, both the preconcentration factor (initial to final concentration ratio) and the facilitation of the mass transport would have effect on the peak current intensity.

For diffusion-controlled electrochemical processes, the peak current in $\mathrm{CV}$ is proportional to the square root of the scan rate following the Randles-Sevcik equation, which for a planar electrode at $25^{\circ} \mathrm{C}$ and a reversible process is [58]:

$$
i_{\mathrm{p}}=\left(2.69 \times 10^{5}\right) \mathrm{n}^{3 / 2} \mathrm{~A} \mathrm{C} \mathrm{D}^{1 / 2} \mathrm{v}^{1 / 2}
$$

where $i_{p}$ is the peak current intensity (A), $n$ the number of transferred electrons in the electrochemical reaction, A the electrode area $\left(\mathrm{cm}^{2}\right), \mathrm{C}$ the bulk concentration of the analyte $\left(\mathrm{mol} \mathrm{cm} \mathrm{cm}^{-3}\right), \mathrm{D}$ the diffusion coefficient of the analyte and $\mathrm{v}$ the scan rate $\left(\mathrm{V} \mathrm{s}^{-1}\right)$. For totally irreversible systems the equation is transformed in [58]: 


$$
i_{\mathrm{p}}=\left(2.99 \times 10^{5}\right) \alpha^{1 / 2} \mathrm{n}^{3 / 2} \mathrm{AC} \mathrm{D}^{1 / 2} \mathrm{v}^{1 / 2}
$$

where $\alpha$ is the transfer coefficient. In any case, there is a relationship between $i_{p}$ and $\mathrm{v}^{1 / 2}$ for diffusion-controlled processes. However, when porous electrodes are involved a change in the mass transport regime may occur. Voltammetry simulated at a porous film modified electrode highlights the effect of the pore size on the peak current [57]. This system is characterised by the interplay between the planar and "thin layer" diffusional regimes. Apart from a change in the potential (as commented before), a change in the current may also occur. There are regions exposed to the bulk solution in which planar diffusion operates and a region in which "thin layer" diffusion effects occur. Paper with conductive ink can be seen also as an array of pillars of different size and shape that takes part of an intrincated network with a common bottom connection, where "thin-layer" effects could predominate. Fig. S5 shows the log-log plot of the peak current vs. scan rate for studies performed with two different DCF concentrations: 5 and $20 \mu \mathrm{M}$. The slope for the highest concentration (Fig. S5A) was 0.77, which neither corresponds to the value of 0.5 , for semi-infinite diffusion of electroactive species to the electrode, nor to the value of 1 expected for an adsorbed electroactive species, according to the equation [58]:

$$
i_{\mathrm{p}}=\left(\mathrm{n}^{2} \mathrm{~F}^{2} / 4 \mathrm{RT}\right) \mathrm{A} \Gamma^{*} \mathrm{v}
$$

where $\mathrm{F}$ is the Faraday's constant, $\mathrm{R}$ the gas constant ( $\mathrm{J}$ $\mathrm{mol}^{-1} \mathrm{~K}^{-1}$ ), $\mathrm{T}$ the temperature $(\mathrm{K})$ and $\Gamma^{*}$ the surface coverage of the adsorbed species $\left(\mathrm{mol} \mathrm{cm} \mathrm{cm}^{-2}\right)$. Then, this could be indicative of the mixed mass transport regime, that includes both, thin-layer and pure diffusion. However, when the study was performed for a lower concentration (5 $\mu \mathrm{M}$ ), the corresponding $\log i_{p}$ vs. $\log \mathrm{v}$ graph (Fig. S5B) provided a higher slope of 0.90 , closer to this of adsorbed species. Previous studies about DCF behaviour on glassy carbon electrodes indicate adsorption- and diffusioncontrolled processes for 5 and $50 \mu \mathrm{M}$ respectively [21]. Slopes higher than 0.5 have also been reported for ferrocyanide on porous paper-templated electrodes $(0.68$ for gold- and 0.90 for platinum paper-templated electrodes) [59].

Apart from the preconcentration of the analyte, a different approach to improve the sensitivity of the method is the use of other electrochemical techniques that are more sensitive than CV. Cyclic Voltammetry is an excellent diagnostic technique but pulse voltammetric techniques increase the iffic ratio (faradaic to capacitive current) and, in turn, the sensitivity. Therefore, besides CV, differential pulse voltammetry (DPV) was also employed (Fig. 2D). Without any preconcentration step, DPV provided a better defined peak with a higher peak current intensity for 20$\mu \mathrm{M}$ DCF solutions (1.4 vs. $0.7 \mu \mathrm{A}$ for LSV). However, when a preconcentration step was carried out, both techniques provided similar peaks in terms of intensity (peak currents of 8.7 and $8.0 \mu \mathrm{A}$ for LSV and DPV, respectively) and definition.
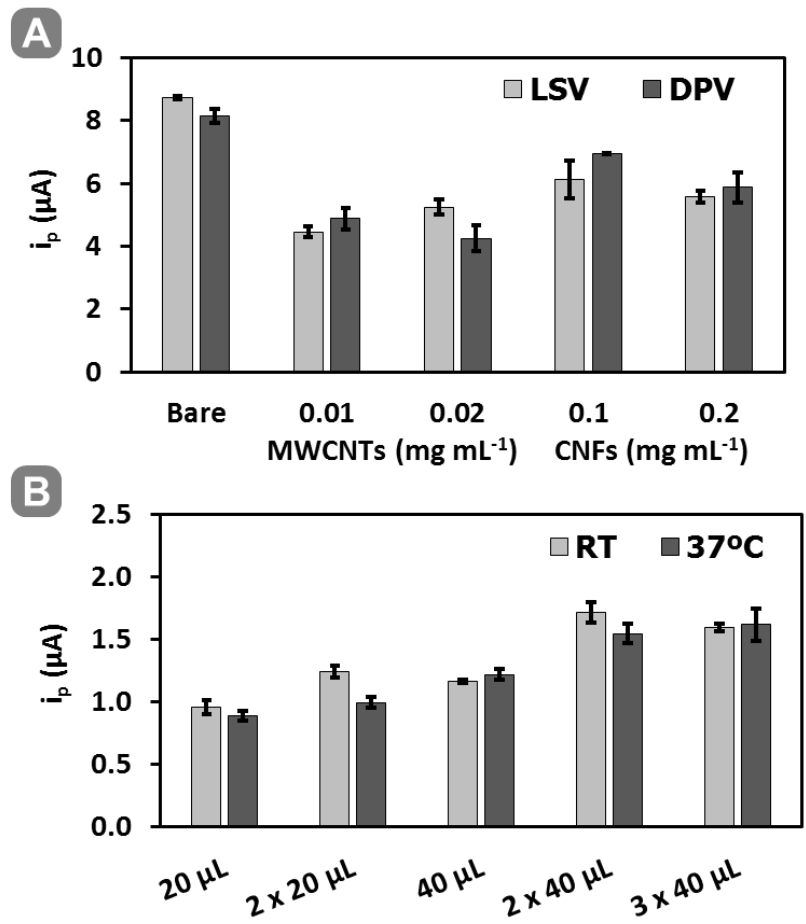

Fig. 3. (A) Peak current intensities obtained by performing LSVs and DPVs in $10 \mu \mathrm{L}$ of $0.1 \mathrm{M} \mathrm{PB} \mathrm{pH} 7.0$ after preconcentration of $40 \mu \mathrm{L}$ of a $20-\mu \mathrm{M}$ DCF solution in water, employing bare and modified (with $2 \mu \mathrm{L}$ of MWCNTs or $5 \mu \mathrm{L}$ of CNFs dispersions of different concentrations) paper-based WEs. (B) Peak current intensities obtained by performing LSVs in $10 \mu \mathrm{L}$ of $0.1 \mathrm{M} \mathrm{PB}$ pH 7.0 after preconcentration of 20 and $40 \mu \mathrm{L}$ of a $1-\mu \mathrm{M}$ DCF solution in water (drying at RT and at $37^{\circ} \mathrm{C}$ ) once, twice and three times. Error bars correspond to the standard deviation of: (A) 3 and (B) 5 measurements. DPV conditions: pulse amplitude: $50 \mathrm{mV}$, pulse width: $80 \mathrm{~ms}$, pulse repetition time: $8 \mathrm{~s}$ and scan rate: $6.25 \mathrm{mV} \mathrm{s}^{-1}$. Scan rate for LSV: $50 \mathrm{mV} \mathrm{s}^{-1}$.

A third possible approach for signal amplification is the use of nanomaterials as electrode surface modifiers that can favour the electron transfer. Therefore, the modification of the paper-based WE with carbon nanomaterials (carbon nanotubes and nanofibers) was considered since they have demonstrated to improve the electron transfer and therefore, the current intensity of redox processes [60-62]. The paper-based WEs were modified with MWCNTs and CNFs dispersions (as explained in Section 2.4) with the aim of amplifying the DCF's anodic process of interest. When LSV was performed on CNF-modified WEs, a better-defined anodic peak appeared, with a slight increase in peak current intensity when compared with signals obtained for unmodified or MWCNT-modified WEs (Fig. S6). However, when the preconcentration was carried out, the highest peak current intensity was obtained with the unmodified WE, not only for LSV, but also for DPV (Fig. 3A). Although carbon materials usually improve electron 
transfer, in this case the modification was made through the paper porous matrix and the nanomaterials may be retained on the cellulose fibres. When the preconcentration procedure was performed, DCF molecules may be retained on the carbon nanomaterials and the mass transport may become disfavoured. This possible mechanism is consistent with the fact that when a double concentration of nanomaterials was employed the current intensities showed a slight decrease (more clear for CNFs). Regarding the reproducibility, unmodified WEs also provided better results than those obtained with the WEs modified with carbon nanomaterials (Fig. 3A). Moreover, in all the situations, LSV and DPV provided very similar results. Thus, a preconcentration on unmodified paperbased WEs was chosen for DCF analysis, and LSV was selected as the detection technique for the sake of simplicity.

\subsection{Voltammetric determination of diclofenac.}

After the conclusion that the preconcentration of DCF on paper-based WEs produced a huge increase in the analytical signal (current intensity of the first anodic peak), the procedure was optimized. There are two main parameters that were considered and evaluated: i) the volume of the DCF solution used in the preconcentration and ii) the temperature of evaporation. Due to the small diameter of the WE ( $4 \mathrm{~mm}$ ), drops larger than $40 \mu \mathrm{L}$ were not employed to avoid the risk of spillage out of the area delimited by the wax. Thus, to test higher volumes, after depositing and drying a $40-\mu \mathrm{L}$ drop of DCF solution, a second $40-\mu \mathrm{L}$ drop was deposited and left to dry $(2 \times 40$ $\mu \mathrm{L})$. This process could be repeated several times and with different volumes (e.g., two $20-\mu \mathrm{L}$ drops). The evaporation of the DCF solution was evaluated at room temperature (RT, ca. $20^{\circ} \mathrm{C}$ ) and at $37^{\circ} \mathrm{C}$. This temperature was chosen since it favours the evaporation without damaging the paper structure or altering the redox behaviour of DCF. Fig. 3B shows the results obtained. The analytical signals obtained at RT and at $37^{\circ} \mathrm{C}$ were very similar; only when the preconcentration was performed in two steps, i.e. $2 \mathrm{x}$ $20 \mu \mathrm{L}$ or $2 \times 40 \mu \mathrm{L}$, the results obtained at RT were slightly better. However, the time needed for evaporating a 40- $\mu \mathrm{L}$ drop at RT was ca. $2 \mathrm{~h}$ vs. $1 \mathrm{~h}$ for evaporating the same drop at $37^{\circ} \mathrm{C}$ (see Table S1). Therefore, the reduction in the analysis time justifies the use of $37^{\circ} \mathrm{C}$. Regarding the volume, the analytical signal increased with the volume preconcentrated (higher number of moles) until $2 \times 40 \mu \mathrm{L}$ (an 8-fold preconcentration). However, for a third preconcentration (i.e. $3 \times 40 \mu \mathrm{L}, 12$ fold), the analytical signal remained the same. When drying was done at RT, the signal was slightly lower, which could indicate the saturation of the WE. Hence, a volume of $80 \mu \mathrm{L}(2 \times 40$ $\mu \mathrm{L}$ ) evaporated at $37^{\circ} \mathrm{C}$ was chosen as the best conditions to carry out the quantification of DCF.
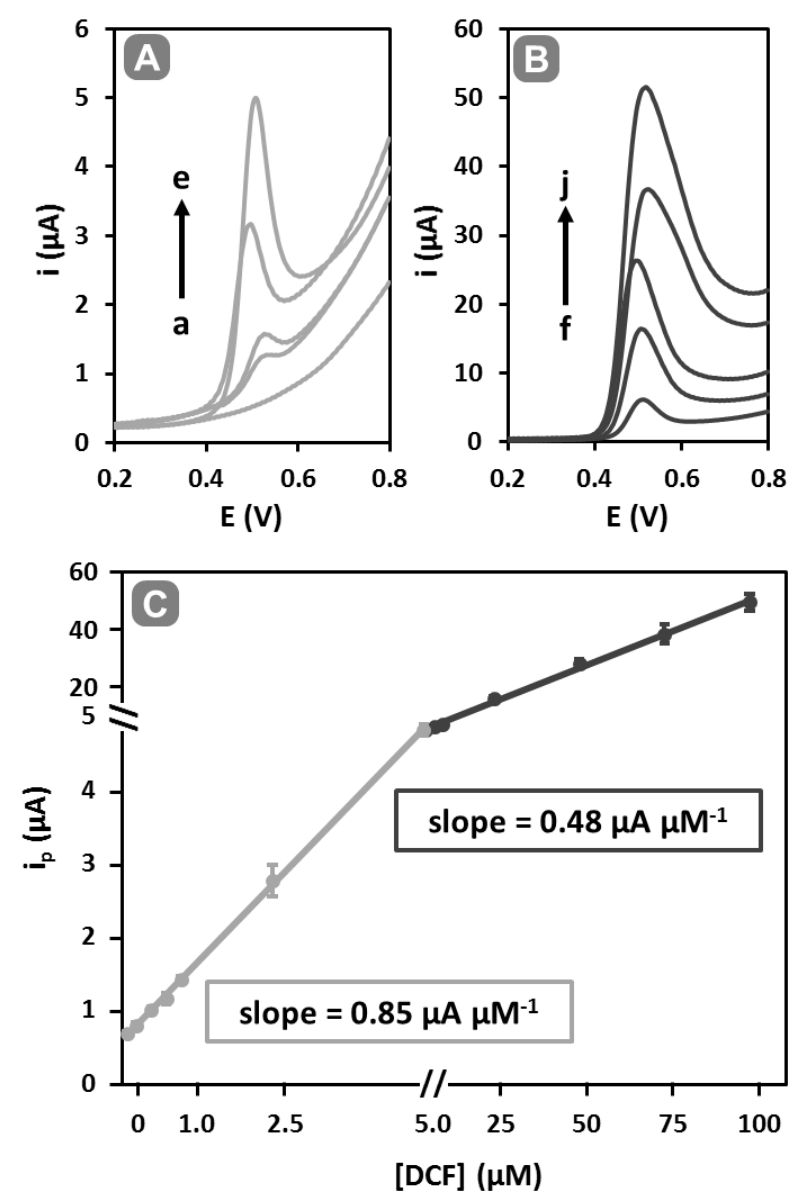

Fig. 4. (A,B) LSVs recorded in $10 \mu \mathrm{L}$ of $0.1 \mathrm{M}$ PB pH 7.0 after preconcentration of $2 \times 40 \mu \mathrm{L}$ at $37^{\circ} \mathrm{C}$ of different DCF concentrations: (a) background, (b) 0.50 , (c) 1.0 , (d) 2.5, (e) 5.0, (f) 7.5, (g) 25, (h) 50, (i) 75 and (j) $100 \mu \mathrm{M}$. (C) Linear dynamic ranges of the calibration curve obtained representing the peak current intensities of the LSVs vs. the DCF concentrations. Error bars correspond to the standard deviation of 5 measurements. Scan rate for LSV: $100 \mathrm{mV} \mathrm{s}^{-1}$.

With the aim of establishing the dynamic range of the methodology, LSVs were recorded on different paperbased WEs on which two $40-\mu \mathrm{L}$ drops of different DCF concentrations were deposited and evaporated at $37^{\circ} \mathrm{C}$. Fig. 4 shows the response of the sensor for DCF concentrations comprised between 0.10 and $100 \mu \mathrm{M}$. A wide dynamic range was obtained (four orders of magnitude) and two linear ranges were observed: one, at low concentrations, from 0.10 to $5.0 \mu \mathrm{M}$, where the process is adsorption-controlled, according to the equation $i_{p}(\mu \mathrm{A})=0.85[\mathrm{DCF}](\mu \mathrm{M})+0.57, \mathrm{R}^{2}=0.9994$; and the other, between 5.0 and $100 \mu \mathrm{M}$ (where the process is diffusion-controlled), according to the equation $i_{p}(\mu \mathrm{A})=$ $0.48[\mathrm{DCF}](\mu \mathrm{M})+2.8, \mathrm{R}^{2}=0.997$. The first range covers one and a half orders of magnitude, and the second one two and a half, which indicates that DCF can be determined in a very wide concentration range. The first calibration line had a slope that was almost twice that of the second one, which is very important to detect low DCF concentrations. Actually, the LOD, calculated as three times the standard deviation of the intercept divided by the 
slope, was $70 \mathrm{nM}$, which was almost 800 -fold lower than this obtained without preconcentration $(55 \mu \mathrm{M}$, Fig. S4).

As can be seen in Table S1, the LOD achieved with this paper-based platform is comparable or, in some cases, better than the reported for other sensors fabricated with conventional electrodes that require complex construction procedures, expensive reagents (ionic liquids, nanomaterials, etc.) and therefore, involve a much higher cost and fabrication time. In order to assess the reproducibility, LSVs were recorded in 0.5 and $50 \mu \mathrm{M}$ DCF solutions employing different paper-based platforms. A very good reproducibility in terms of RSD was obtained, with values of $4.6 \%(n=7)$ and $5.3 \%(n=7)$ for the low and high concentrations, respectively. This can be seen also in the error bars of the calibration curve (Fig. 4C), where the average of 5 measurements was considered for each concentration.

The paper-based platform was employed for the determination of DCF in spiked tap water (collected from the water network of the metropolitan area of Oviedo; see Table S3 with parameters monitored by Aqualia, the water supplier). No sample pretreatment was required. In Fig. S7 the LSVs obtained are shown. Table 1 shows the results achieved for tap water samples that were spiked to obtain 0.5 and $50 \mu \mathrm{M}$ DCF concentrations. Recoveries of $100.2 \%$ and $94.2 \%$ were obtained, respectively, showing the accuracy of the methodology for DCF analysis.

Table 1. Results of the recovery test of the proposed method for the determination of DCF in spiked tap water (average data \pm standard deviation is indicated for $\mathrm{n}=3$ ).

\begin{tabular}{ccc}
\hline $\begin{array}{c}\text { DCF added } \\
(\mu \mathrm{M})\end{array}$ & $\begin{array}{c}\text { DCF found } \\
(\mu \mathrm{M})\end{array}$ & $\begin{array}{c}\text { Recovery } \\
(\%)\end{array}$ \\
\hline 0.5 & $0.50 \pm 0.02$ & $100.2 \pm 4.7$ \\
50 & $47.1 \pm 2.8$ & $94.2 \pm 5.5$ \\
\hline
\end{tabular}

\subsection{Multiplexed paper-based platform.}

Together with the cost, analysis time is nowadays one of the more valuable variables of a methodology. Cheap, fast and simple procedures that can be performed at the pointof-need are among the most meaningful and challenging requirements, besides accuracy, precision and sensitivity. As commented in the previous section, preconcentration increased analysis time and performing several preconcentrations simultaneously -as well as measurements- would be very advantageous. We have taken advantage of the versatility of this paper platform and have constructed a multiplexed platform consisting of eight independent electrochemical cells, as shown in Fig. 1B. With the aim of evaluating its performance, LSVs were recorded in $10 \mu \mathrm{L}$ of buffer solution after the preconcentration of a $2.5-\mu \mathrm{M}$ DCF solution $(2 \times 40 \mu \mathrm{L}$, $37^{\circ} \mathrm{C}$ ) employing three different platforms. The peak current intensities obtained for each one of the electrochemical cells are represented in Fig. 5A. The average of all the peak current intensities obtained was 1.9 $\pm 0.1 \mu \mathrm{A} \quad(\mathrm{RSD}=5.3 \%)$ demonstrating the good reproducibility, especially considering the simplicity of the hand-made platform.
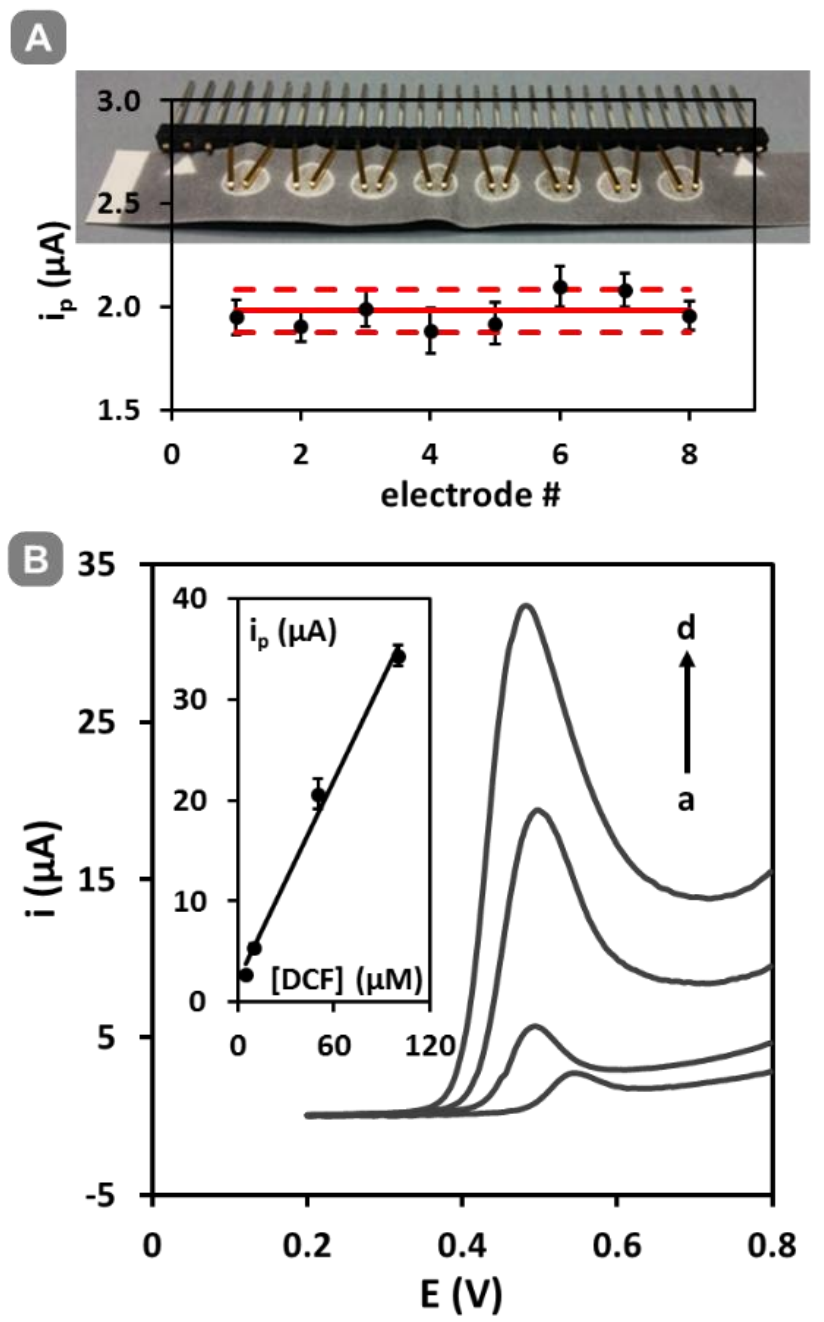

Fig. 5. (A) Peak current intensities obtained by performing LSVs in $10 \mu \mathrm{L}$ of $0.1 \mathrm{M} \mathrm{PB} \mathrm{pH} 7.0$ after preconcentration of $2 \times 40 \mu \mathrm{L}$, at $37^{\circ} \mathrm{C}$, of $2.5 \mu \mathrm{M}$ DCF employing the 8 -WE paper-based platform (error bars correspond to the standard deviation of 3 measurements performed in different multiplexed paper-based platforms). The red lines represent the average $\pm S D$ of 24 measurements. (B) LSVs recorded in $10 \mu \mathrm{L}$ of $0.1 \mathrm{M} \mathrm{PB} \mathrm{pH} 7$ after preconcentration of $2 \times 40 \mu \mathrm{L}$, at $37^{\circ} \mathrm{C}$, of DCF solutions with concentrations: (a) 5, (b) 10, (c) 50 and (d) $100 \mu \mathrm{M}$. Inset: linear dynamic range of the calibration curve. Error bars correspond to the standard deviation of 6 measurements (two measurements for each concentration, performed in 3 different multiplexed paper-based platform). Scan rate for LSV: $100 \mathrm{mV} \mathrm{s}$ 1.

Once the precision of the paper-based multiplexed device was confirmed, its utility for DCF analysis was assessed. Thus, LSVs were recorded in buffer solution after the preconcentration of DCF solutions of different concentrations $(5,10,50$ and $100 \mu \mathrm{M})$. The results, obtained with the multichannel potentiostat, are shown in 
Fig. 5B. As expected, a linear relationship between peak current intensity and DCF concentration was obtained and the corresponding regression equation was: $i_{p}(\mu \mathrm{A})=0.33$ $[D C F](\mu \mathrm{M})+2.1\left(\mathrm{R}^{2}=0.991\right)$. This demonstrates the great versatility of this platform, maintaining its good analytical characteristics. Moreover, since paper enables multiple designs and connector headers with more pins are commercially available and are easily customized, this simple construction allows to achieve platforms with a myriad of designs and electrochemical cells.

\section{Conclusions}

Since many paper-based analytical platforms sacrifice sensitivity for simplicity, the development of new strategies to improve it is still a challenge. In this work the first paper-based platform for the determination of DCF was developed. DCF is a widely used drug and its analysis is of paramount importance not only in pharmaceutical industries, for quality and therapeutical control purposes, but also in surface waters because of its frequent occurrence and potential toxicity, being considered an emerging contaminant. The main novelty of this platform is that it enabled a simple strategy for preconcentrating the analyte on the same paper-based WE where detection is performed. Thus, it integrated different steps, preconcentration and detection, in a single device (lab-onpaper). This produced a huge increase in the sensitivity of the electrochemical detection of ca. 60 fold $\left(0.85 \mu \mathrm{A} \mu \mathrm{M}^{-1}\right.$

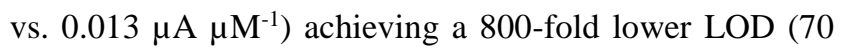
$\mathrm{nM}$ vs. $55 \mu \mathrm{M}$ ). Other interesting advantages of this platform is that it allowed to decouple sample from detection volumes and the medium in which the measurement is performed can be different from the initial one. Moreover, its low cost and small size enable to perform decentralized measurements, which is very interesting especially for enviromental analysis. The great versatility of this design allows to construct very precise multiplexed platforms consisting of numerous independent electrochemical cells with the only limitation imposed by the capability of the potentiostat. The good results obtained suggest that this easy-to-handle platform could be successfully applied, with the advantageous preconcentration strategy, for the analysis of other analytes that require high sensitivity.

\section{Acknowledgements}

The authors would like to thank the EU and FCT / UEFISCDI / FORMAS for funding, in the frame of the collaborative international consortium REWATER financed under the ERA-NET Cofund WaterWorks 2015 Call. This ERA-NET is an integral part of the 2016 Joint Activities developed by the Water Challenges for a Changing World Joint Programme Initiative (Water JPI).
This work was also supported by the EU (FEDER funds throught COMPETE) and FCT (project FOODnanoHEALTH, Portugal2020, Norte-01-0145FEDER-000011 and project UID/QUI/50006/2013) and by the Spanish Ministry of Economy and Competitiveness (MINECO, project CTQ2014-58826-R). Estefanía Costa Rama thanks the Government of Principado de Asturias and Marie Curie-Cofund Actions for the post-doctoral grant "Clarín-Cofund" ACA17-20.

\section{Supplementary material}

Supplementary data associated with this article can be found in the online version.

\section{References}

[1] R. Altman, B. Bosch, K. Brune, P. Patrignani, C. Young, Advances in NSAID development: Evolution of diclofenac products using pharmaceutical technology, Drugs. 75 (2015) 859-877. doi:10.1007/s40265-0150392-z.

[2] T.J. Gan, Diclofenac: an update on its mechanism of action and safety profile, Curr. Med. Res. Opin. 26 (2010) 1715-1731. doi:10.1185/03007995.2010.486301.

[3] R.R. Cunha, D.T. Gimenes, R.A.A. Munoz, C.L. Do Lago, E.M. Richter, Simultaneous determination of diclofenac and its common counter-ions in less than 1 minute using capillary electrophoresis with contactless conductivity detection, Electrophoresis. 34 (2013) 14231428. doi:10.1002/elps.201300008.

[4] M.S. García, M.I. Albero, C. Sánchez-Pedreño, J. Molina, Flow-injection spectrophotometric determination of diclofenac sodium in pharmaceuticals and urine samples, J. Pharm. Biomed. Anal. 17 (1998) 267-273. doi:10.1016/S0731-7085(97)00195-7.

[5] M. Petrović, M.D. Hernando, M.S. Díaz-Cruz, D. Barceló, Liquid chromatography-tandem mass spectrometry for the analysis of pharmaceutical residues in environmental samples: A review, J. Chromatogr. A. 1067 (2005) 1-14. doi:10.1016/j.chroma.2004.10.110.

[6] T.T.K. Nguyen, T.T. Vu, G. Anquetin, H. V Tran, S. Reisberg, V. Noël, G. Mattana, Enzyme-less electrochemical displacement heterogeneous immunosensor for diclofenac detection, Biosens. Bioelectron. $\quad 97 \quad$ (2017) 246-252. doi:10.1016/j.bios.2017.06.010.

[7] M. Goodarzian, M.A. Khalilzade, F. Karimi, V. Kumar Gupta, M. Keyvanfard, H. Bagheri, M. Fouladgar, Square wave voltammetric determination of diclofenac in liquid phase using a novel ionic liquid multiwall carbon nanotubes paste electrode, J. Mol. Liq. 197 (2014) 114-119. doi:10.1016/j.molliq.2014.04.037.

[8] P. Paíga, L.H.M.L.M. Santos, S. Ramos, S. Jorge, J.G. Silva, C. Delerue-Matos, Presence of pharmaceuticals in the Lis river (Portugal): Sources, fate and seasonal variation, Sci. Total Environ. 573 (2016) 164-177. doi:10.1016/j.scitotenv.2016.08.089.

[9] L. Lonappan, S.K. Brar, R.K. Das, M. Verma, R.Y. Surampalli, Diclofenac and its transformation products: Environmental occurrence and toxicity - A review, 
Environ. Int. $96 \quad$ (2016) 127-138. doi:10.1016/j.envint.2016.09.014.

[10] Y. Zhang, S.U. Geißen, C. Gal, Carbamazepine and diclofenac: Removal in wastewater treatment plants and occurrence in water bodies, Chemosphere. 73 (2008) 1151-1161. doi:10.1016/j.chemosphere.2008.07.086.

[11] B. Petrie, R. Barden, B. Kasprzyk-Hordern, A review on emerging contaminants in wastewaters and the environment: Current knowledge, understudied areas and recommendations for future monitoring, Water Res. 72 (2014) 3-27. doi:10.1016/j.watres.2014.08.053.

[12] S.D. Richardson, T.A. Ternes, Water analysis: Emerging contaminants and current issues, Anal. Chem. 86 (2014) 2813-2848. doi:10.1021/ac500508t.

[13] B. Albero, C. Sánchez-Brunete, A.I. García-Valcárcel, R.A. Pérez, J.L. Tadeo, Ultrasound-assisted extraction of emerging contaminants from environmental samples, TrAC - Trends Anal. Chem. 71 (2015) 110-118. doi:10.1016/j.trac.2015.03.015.

[14] Q. Sui, X. Cao, S. Lu, W. Zhao, Z. Qiu, G. Yu, Occurrence, sources and fate of pharmaceuticals and personal care products in the groundwater: A review, Emerg. Contam. 1 (2015) 14-24. doi:10.1016/j.emcon.2015.07.001.

[15] Y. Luo, W. Guo, H.H. Ngo, L.D. Nghiem, F.I. Hai, J. Zhang, S. Liang, X.C. Wang, A review on the occurrence of micropollutants in the aquatic environment and their fate and removal during wastewater treatment, Sci. Total Environ. 473-474 (2014) 619-641. doi:10.1016/j.scitotenv.2013.12.065.

[16] B. Hoeger, B. Köllner, D.R. Dietrich, B. Hitzfeld, Water-borne diclofenac affects kidney and gill integrity and selected immune parameters in brown trout (Salmo trutta f. fario), Aquat. Toxicol. 75 (2005) 53-64. doi:10.1016/j.aquatox.2005.07.006.

[17] R. Triebskorn, H. Casper, V. Scheil, J. Schwaiger, Ultrastructural effects of pharmaceuticals (carbamazepine, clofibric acid, metoprolol, diclofenac) in rainbow trout (Oncorhynchus mykiss) and common carp (Cyprinus carpio), Anal. Bioanal. Chem. 387 (2007) 1405-1416. doi:10.1007/s00216-006-1033-x.

[18] A.J. Ebele, M. Abou-Elwafa Abdallah, S. Harrad, Pharmaceuticals and personal care products (PPCPs) in the freshwater aquatic environment, Emerg. Contam. 3 (2017) 1-16. doi:10.1016/j.emcon.2016.12.004.

[19] A.A. Gouda, M.I.K. El-sayed, A.S. Amin, R. El, Spectrophotometric and spectrofluorometric methods for the determination of non-steroidal anti-inflammatory drugs: A review, Arab. J. Chem. 6 (2013) 145-163. doi:10.1016/j.arabjc.2010.12.006.

[20] D.T. Gimenes, R.R. Cunha, M.M.A.D.C. Ribeiro, P.F. Pereira, R.A.A. Muñoz, E.M. Richter, Two new electrochemical methods for fast and simultaneous determination of codeine and diclofenac, Talanta. 116 (2013) 1026-1032. doi:10.1016/j.talanta.2013.08.020.

[21] M.C. Blanco-López, M.J. Lobo-Castañón, A.J. MirandaOrdieres, P. Tuñón-Blanco, Voltammetric response of diclofenac-molecularly imprinted film modified carbon electrodes, Anal. Bioanal. Chem. 377 (2003) 257-261. doi:10.1007/s00216-003-2019-6.

[22] M.C. Blanco-López, L. Fernández-Llano, M.J. LoboCastañón, A.J. Miranda-Ordieres, P. Tuñón-Blanco, Voltammetry of diclofenac at graphite, carbon composites, and molecularly imprinted polymercomposite electrodes, Anal. Lett. 37 (2004) 915-927. doi:10.1081/AL-120030287.

[23] H. Razmi, K. Sarhang-Zadeh, R. Mohammad-Rezaei, Electrochemical behavior and voltammetric determination of diclofenac at a multi-walled carbon nanotube-ionic liquid composite modified carbon ceramic electrode, Anal. Lett. 46 (2013) 1885-1896. doi:10.1080/00032719.2013.777919.

[24] K. Sarhangzadeh, A.A. Khatami, M. Jabbari, S. Bahari, Simultaneous determination of diclofenac and indomethacin using a sensitive electrochemical sensor based on multiwalled carbon nanotube and ionic liquid nanocomposite, J. Appl. Electrochem. 43 (2013) 1217 1224. doi:10.1007/s10800-013-0609-3.

[25] F. Basiri, M. Taei, Application of spinel-structured $\mathrm{MgFe} 2 \mathrm{O} 4$ nanoparticles for simultaneous electrochemical determination diclofenac and morphine, Microchim. Acta. 184 (2017) 155-162. doi:10.1007/s00604-016-1995-0.

[26] A. Afkhami, A. Bahiraei, T. Madrakian, Gold nanoparticle/multi-walled carbon nanotube modified glassy carbon electrode as a sensitive voltammetric sensor for the determination of diclofenac sodium, Mater. Sci. Eng. C. 59 (2016) 168-176. doi:10.1016/j.msec.2015.09.097.

[27] M.M. El-Wekil, S.A. Alkahtani, H.R.H. Ali, A.M Mahmoud, Advanced sensing nanomaterials based carbon paste electrode for simultaneous electrochemical measurement of esomeprazole and diclofenac sodium in human serum and urine samples, J. Mol. Liq. 262 (2018) 495-503. doi:10.1016/j.molliq.2018.04.120.

[28] L. Fernández-Llano, M.C. Blanco-López, M.J. LoboCastañón, A.J. Miranda-Ordieres, P. Tuñón-Blanco, Determination of diclofenac in urine samples by molecularly-imprinted solid-phase extraction and adsorptive differential pulse voltammetry, Electroanalysis. $19 \quad$ (2007) 1555-1561. doi:10.1002/elan.200703895.

[29] M.C. Oliveira, E.H. Bindewald, L.H. Marcolino, M.F. Bergamini, Potentiometric determination of diclofenac using an ion-selective electrode prepared from polypyrrole films, J. Electroanal. Chem. 732 (2014) 1116. doi:10.1016/j.jelechem.2014.08.006.

[30] J. Lenik, A new potentiometric electrode incorporating functionalized $\beta$-cyclodextrins for diclofenac determination, Mater. Sci. Eng. C. 45 (2014) 109-116. doi:10.1016/j.msec.2014.08.072.

[31] H. Derikvand, M. Roushani, A.R. Abbasi, Z. Derikvand, A. Azadbakht, Design of folding-based impedimetric aptasensor for determination of the nonsteroidal antiinflammatory drug, Anal. Biochem. 513 (2016) 77-86. doi:10.1016/j.ab.2016.06.013.

[32] C. Karuppiah, S. Cheemalapati, S.M. Chen, S. Palanisamy, Carboxyl-functionalized graphene oxidemodified electrode for the electrochemical determination of nonsteroidal anti-inflammatory drug diclofenac, Ionics (Kiel). 21 (2015) 231-238. doi:10.1007/s11581014-1161-9.

[33] A. Azadbakht, S. Beirnvand, Voltammetric aptamerbased switch probes for sensing diclofenac using a glassy carbon electrode modified with a composite prepared from gold nanoparticles, carbon nanotubes and amino-functionalized Fe3O4 nanoparticles, Microchim. 
Acta. 184 (2017) 2825-2835. doi:10.1007/s00604-0172285-1.

[34] M. Shalauddin, S. Akhter, S. Bagheri, M.S. Abd Karim, N. Adib Kadri, W.J. Basirun, Immobilized copper ions on MWCNTS-Chitosan thin film: Enhanced amperometric sensor for electrochemical determination of diclofenac sodium in aqueous solution, Int. J. Hydrogen Energy. 42 (2017) 19951-19960. doi:10.1016/j.ijhydene.2017.06.163.

[35] M. Arvand, T.M. Gholizadeh, M.A. Zanjanchi, MWCNTs/Cu(OH)2 nanoparticles/IL nanocomposite modified glassy carbon electrode as a voltammetric sensor for determination of the non-steroidal antiinflammatory drug diclofenac, Mater. Sci. Eng. C. 32 (2012) 1682-1689. doi:10.1016/j.msec.2012.04.066.

[36] L. Kashefi-Kheyrabadi, M.A. Mehrgardi, Design and construction of a label free aptasensor for electrochemical detection of sodium diclofenac, Biosens. Bioelectron. 33 (2012) 184-189. doi:10.1016/j.bios.2011.12.050.

[37] T. Rungsawang, E. Punrat, J. Adkins, C. Henry, Development of Electrochemical Paper-based Glucose Sensor Using Cellulose-4-aminophenylboronic Acidmodified Screen-printed Carbon Electrode, Electroanalysis. (2016) 462-468. doi:10.1002/elan.201500406.

[38] W. Dungchai, O. Chailapakul, C.S. Henry, Electrochemical detection for paper-based microfluidics, Anal. Chem. $81 \quad$ (2009) 5821-5826. doi:10.1021/ac9007573.

[39] J. Wang, Electrochemical biosensors: Towards point-ofcare cancer diagnostics, Biosens. Bioelectron. 21 (2006) 1887-1892. doi:10.1016/j.bios.2005.10.027.

[40] M.I.G.S. Almeida, B.M. Jayawardane, S.D. Kolev, I.D. McKelvie, Developments of microfluidic paper-based analytical devices ( $\mu$ PADs) for water analysis: A review, Talanta. $\quad 177 \quad$ (2018) 176-190. doi:10.1016/j.talanta.2017.08.072.

[41] C. Parolo, A. Merkoçi, Paper-based nanobiosensors for diagnostics, Chem. Soc. Rev. 42 (2013) 450-457. doi:10.1039/C2CS35255A.

[42] N.A. Meredith, C. Quinn, D.M. Cate, T.H. Reilly, J. Volckens, C.S. Henry, Paper-based analytical devices for environmental analysis, Analyst. 141 (2016) 18741887. doi:10.1039/C5AN02572A.

[43] D.M. Cate, J.A. Adkins, J. Mettakoonpitak, C.S. Henry, Recent developments in paper-based microfluidic devices, Anal. Chem. 87 (2015) 19-41. doi:10.1021/ac503968p.

[44] Y. Yang, E. Noviana, M.P. Nguyen, B.J. Geiss, D.S. Dandy, C.S. Henry, Paper-based microfluidic devices: emerging themes and applications, Anal. Chem. 89 (2017) 71-91. doi:10.1021/acs.analchem.6b04581.

[45] A.W. Martinez, S.T. Phillips, G.M. Whitesides, E. Carrilho, Diagnostics for the developing world: Microfluidic paper-based analytical devices, Anal. Chem. 82 (2010) 3-10. doi:10.1021/ac9013989.

[46] J. Mettakoonpitak, K. Boehle, S. Nantaphol, P. Teengam, J.A. Adkins, M. Srisa-Art, C.S. Henry, Electrochemistry on paper-based analytical devices: A Review, Electroanalysis. 28 (2016) 1420-1436. doi:10.1002/elan.201501143.

K. Mahato, A. Srivastava, P. Chandra, Biosensors and
Bioelectronics Paper based diagnostics for personalized health care: Emerging technologies and commercial aspects, Biosens. Bioelectron. 96 (2017) 246-259. doi:10.1016/j.bios.2017.05.001

[48] J. Hu, S.Q. Wang, L. Wang, F. Li, B. Pingguan-Murphy, T.J. Lu, F. Xu, Advances in paper-based point-of-care diagnostics, Biosens. Bioelectron. 54 (2014) 585-597. doi:10.1016/j.bios.2013.10.075.

[49] E. Núnez-Bajo, M.C. Blanco-López, A. Costa-García, M.T. Fernández-Abedul, Integration of gold-sputtered electrofluidic paper on wire-included analytical platforms for glucose biosensing, Biosens. Bioelectron. 91 (2017) 824-832. doi:10.1016/j.bios.2017.01.029.

[50] S. Cinti, M. Basso, D. Moscone, F. Arduini, A paperbased nanomodified electrochemical biosensor for ethanol detection in beers, Anal. Chim. Acta. 960 (2017) 123-130. doi:10.1016/j.aca.2017.01.010.

[51] N. Dossi, R. Toniolo, F. Impellizzieri, F. Tubaro, G. Bontempelli, F. Terzi, E. Piccin, A paper-based platform with a pencil-drawn dual amperometric detector for the rapid quantification of ortho-diphenols in extravirgin olive oil, Anal. Chim. Acta. 950 (2017) 41-48. doi:10.1016/j.aca.2016.11.030.

[52] O. Amor-Gutiérrez, E. Costa Rama, A. Costa-García, M.T. Fernández-Abedul, Paper-based maskless enzymatic sensor for glucose determination combining ink and wire electrodes, Biosens. Bioelectron. 93 (2017) 40-45. doi:10.1016/j.bios.2016.11.008.

[53] M.M. Cid-Cerón, D.S. Guzmán-Hernández, M.T Ramírez-Silva, A. Galano, M. Romero-Romo, M. Palomar-Pardavé, New insigths on the kinetics and mechanism of the electrochemical oxidation of diclofenac in neutral aqueous medium, Electrochim. Acta. $199 \quad$ (2016) 92-98. doi:10.1016/j.electacta.2016.03.094.

[54] R.N. Goyal, S. Chatterjee, B. Agrawal, Electrochemical investigations of diclofenac at edge plane pyrolytic graphite electrode and its determination in human urine, Sensors Actuators B. Chem. 145 (2010) 743-748. doi:10.1016/j.snb.2010.01.038.

[55] M.C. Henstridge, E.J.F. Dickinson, M. Aslanoglu, C. Batchelor-mcauley, R.G. Compton, Voltammetric selectivity conferred by the modification of electrodes using conductive porous layers or films: The oxidation of dopamine on glassy carbon electrodes modified with multiwalled carbon nanotubes, Sensors Actuators B. $\begin{array}{llll}\text { Chem. } & 145 & \text { (2010) }\end{array}$ doi:10.1016/j.snb.2009.12.046.

[56] M.J. Sims, N. V Rees, E.J.F. Dickinson, R.G. Compton, Effects of thin-layer diffusion in the electrochemical detection of nicotine on basal plane pyrolytic graphite ( BPPG ) electrodes modified with layers of multi-walled carbon nanotubes ( MWCNT-BPPG ), Sensors Actuators B. Chem. 144 (2010) 153-158. doi:10.1016/j.snb.2009.10.055.

[57] M.C. Henstridge, E.J.F. Dickinson, R.G. Compton, Mass Transport to and within Porous Electrodes . Linear Sweep Voltammetry and the Effects of Pore Size: The Prediction of Double Peaks for a Single Electrode Process 1 , 2, Russ. J. Electrochem. 48 (2012) 629-635. doi:10.1134/S1023193512060043.

[58] A.J. Bard, L.R. Faulkner, Electrochemical methods: fundamentals and applications, 2nd ed., John Wiley \& Sons, 2001. 
[59] D.C. Christodouleas, F.C. Simeone, A. Tayi, S. Targ, J.C. Weaver, K. Jayaram, M.T. Fernández-abedul, G.M. Whitesides, Fabrication of Paper-Templated Structures of Noble Metals, Adv. Mater. Technol. 2 (2017) 1600229. doi:10.1002/admt.201600229.

[60] P. Fanjul-Bolado, P. Queipo, P.J. Lamas-Ardisana, A. Costa-García, Manufacture and evaluation of carbon nanotube modified screen-printed electrodes as electrochemical tools, Talanta. 74 (2007) 427-433. doi:10.1016/j.talanta.2007.07.035.

[61] M.T. Fernández-Abedul, A. Costa-García, Carbon nanotubes (CNTs)-based electroanalysis, Anal. Bioanal. Chem. 390 (2008) 293-298. doi:10.1007/s00216-0071686-0.

[62] R. García-González, A. Costa-García, M.T. FernándezAbedul, Enhanced detection of the potential electroactive label methylene blue by electrode nanostructuration with carbon nanotubes, Sensors Actuators, B Chem. 202 (2014) 129-136. doi:10.1016/j.snb.2014.04.104. 
Supporting Data

Preconcentration and sensitive determination of the anti-inflammatory drug diclofenac on a paper-based electroanalytical platform

E. Costa-Rama ${ }^{a *}$, H.P.A. Nouws ${ }^{a}$, C. Delerue-Matos ${ }^{a}$, M.C. Blanco-López ${ }^{b}$, M. T. Fernández-Abedul ${ }^{\mathrm{b} * *}$

${ }^{\text {a } R E Q U I M T E / L A Q V, ~ I n s t i t u t o ~ S u p e r i o r ~ d e ~ E n g e n h a r i a ~ d o ~ P o r t o, ~ I n s t i t u t o ~ P o l i t e ́ c n i c o ~ d o ~}$ Porto, Dr. António Bernardino de Almeida 431, 4200-072 Porto, Portugal

${ }^{\mathrm{b}}$ Departamento de Química Física y Analítica, Universidad de Oviedo, 33006 Oviedo, Spain e-mails: **mtfernandeza@uniovi.es; *estefaniarama@graq.isep.ipp.pt 


\section{A}

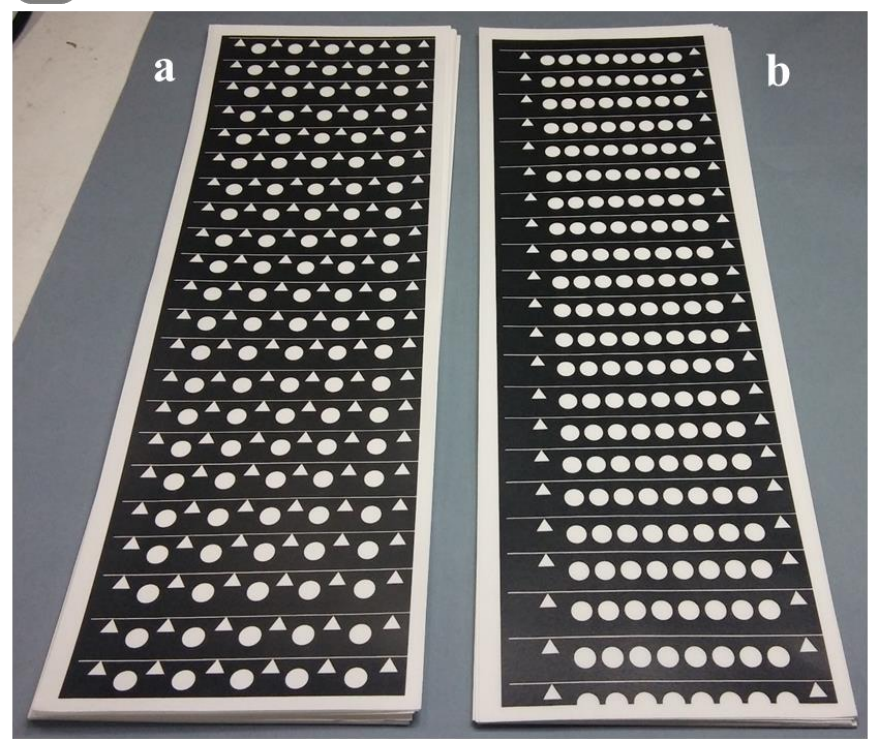

B

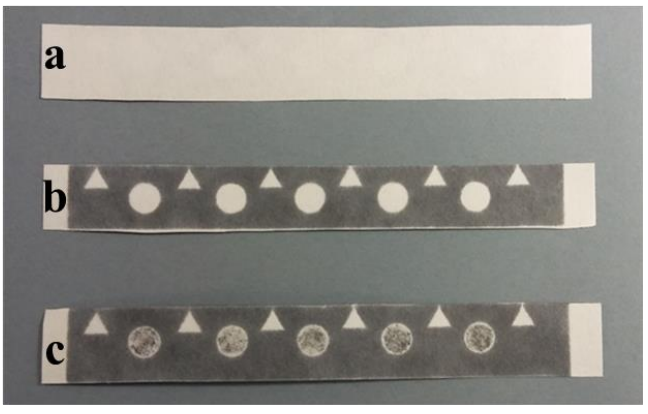

TOP

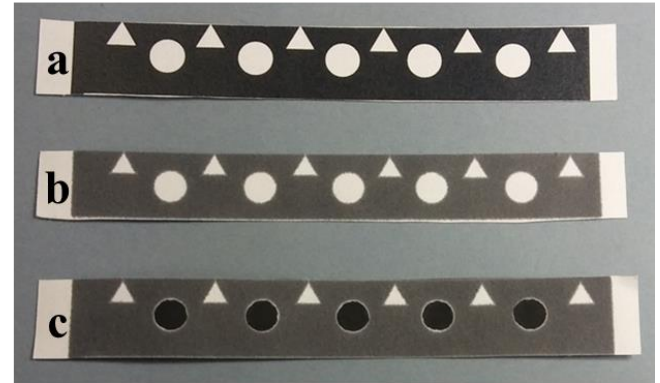

BOTTOM

Fig. S1. (A) Pictures of wax patterns printed on chromatographic paper for constructing: (a) single-WE and (b) multiplexed paper-based electrochemical platforms. (B) Pictures of wax patterns on chromatographic paper after: (a) wax printing, (b) wax diffusion and (c) carbon ink deposition. Triangles indicate the way in which the paper-based WE is clipped.<smiles>O=C(O)Cc1ccccc1Nc1c(Cl)cccc1Cl</smiles>

Fig. S2. Structure of diclofenac (fully protonated). 


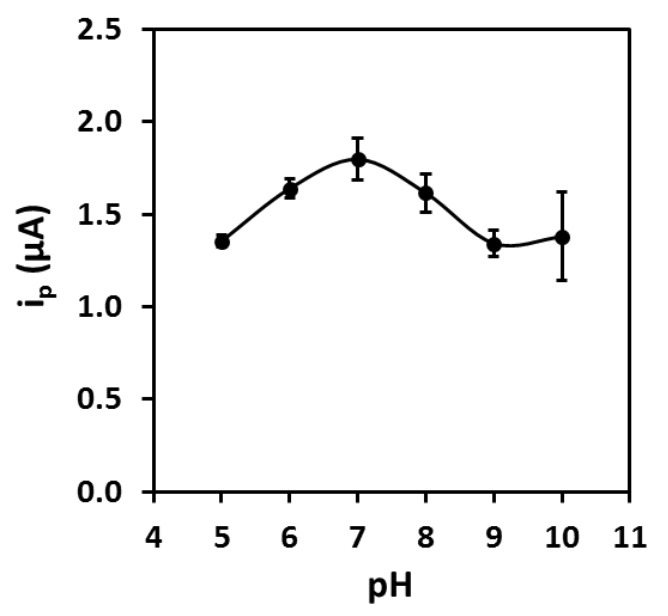

Fig. S3. Peak current intensities obtained by LSV for $10 \mu \mathrm{L}$ of $50 \mu \mathrm{M}$ DCF in BrittonRobinson buffer solutions with $\mathrm{pH}$ values comprised between 5 and 10. Error bars correspond to the standard deviation of 3 measurements.

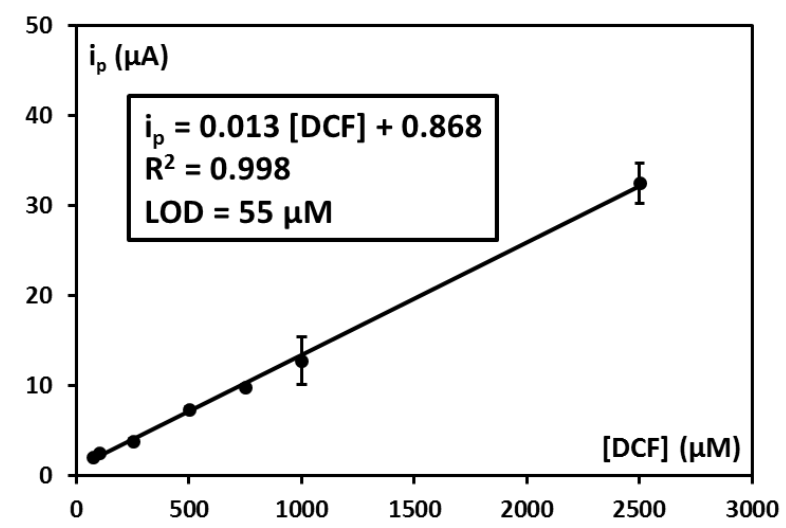

Fig. S4. Calibration curve (peak current intensity vs. DCF concentration) obtained recording LSVs in $10 \mu \mathrm{L}$ DCF solutions of different concentrations (75, 100, 250, 500, 750, 1000 and $2500 \mu \mathrm{M}$ ) in $0.1 \mathrm{M} \mathrm{PB} \mathrm{pH} \mathrm{7.0.} \mathrm{Error} \mathrm{bars} \mathrm{correspond} \mathrm{to} \mathrm{the} \mathrm{standard} \mathrm{deviation} \mathrm{of} 3$ measurements. Scan rate: $50 \mathrm{mV} \mathrm{s}^{-1}$. 

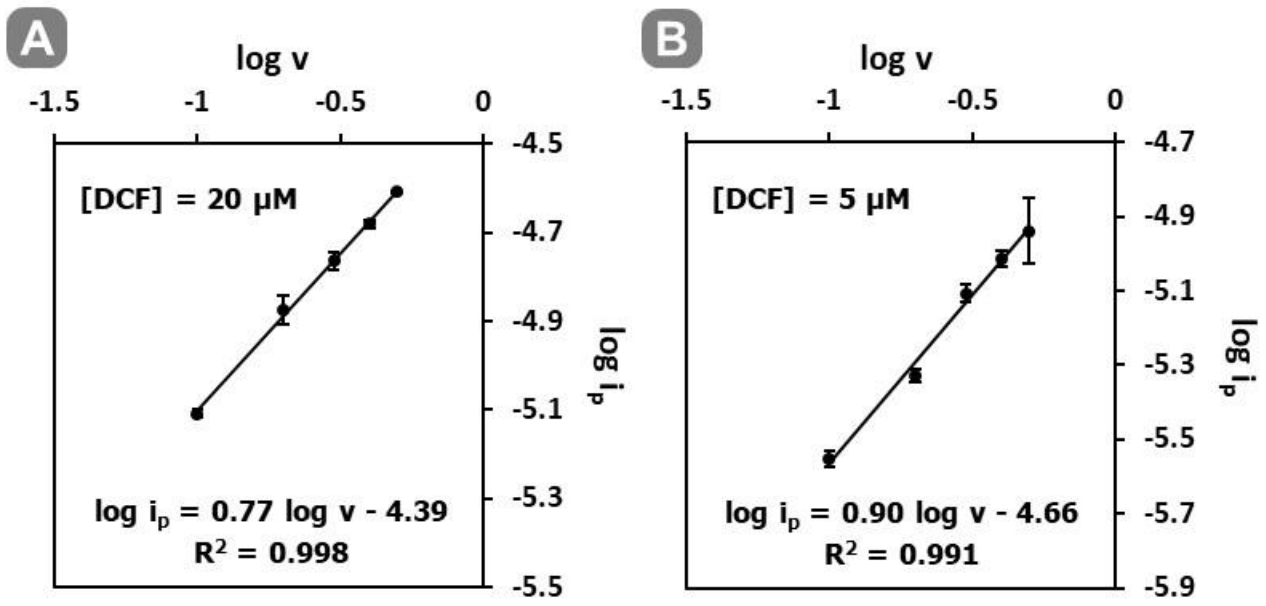

Fig. S5. Representation of the logarithmic plot of peak current intensities vs. scan rate, obtained by $\mathrm{CV}$ performed in $10 \mu \mathrm{L}$ of $0.1 \mathrm{M} \mathrm{PB} \mathrm{pH} 7.0$ after preconcentration of $40 \mu \mathrm{L}$ of (A) 20 and (B) $5 \mu \mathrm{M}$ DCF solutions in water (error bars correspond to the standard deviation of 3 measurements).

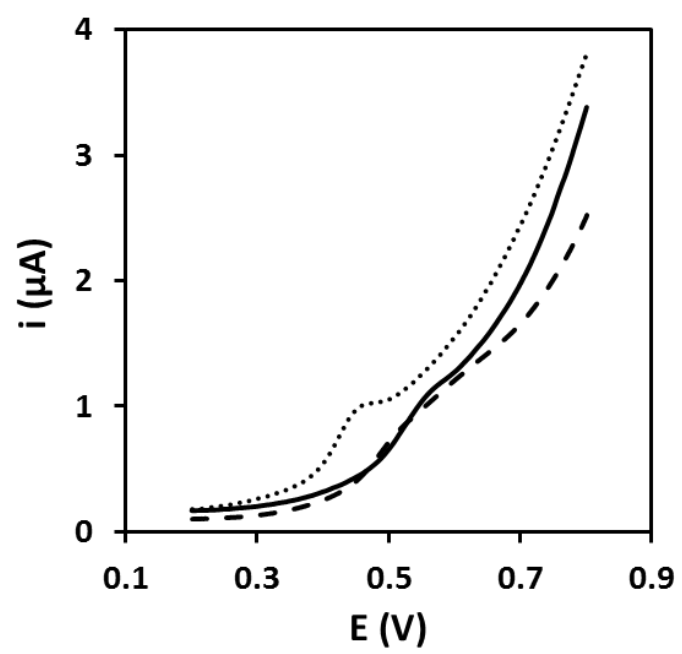

Fig. S6. LSVs performed in $10 \mu \mathrm{L}$ of a $20-\mu \mathrm{M}$ DCF solution in $0.1 \mathrm{M}$ PB pH 7.0 employing a bare paper-based WE (solid line), WEs modified with $2 \mu \mathrm{L}$ of $0.01-\mathrm{mg} \mathrm{mL}^{-1}$ MWCNTs (dashed line) and $5 \mu \mathrm{L}$ of $0.1-\mathrm{mg} \mathrm{mL}^{-1} \mathrm{CNFs}$ (dotted line) dispersions. Scan rate: $50 \mathrm{mV} \mathrm{s}^{-1}$. 
Table S1. Drying times for different volumes of DCF solution at room temperature $\left(20^{\circ} \mathrm{C}\right)$ and in the oven $\left(37^{\circ} \mathrm{C}\right)$.

\begin{tabular}{|c|c|c|}
\cline { 2 - 3 } \multicolumn{1}{c|}{} & \multicolumn{2}{c|}{ Drying time } \\
\hline Temperature & $\mathbf{2 0 ^ { 0 } \mathrm { C }}$ & $\mathbf{3 7}^{\mathbf{}} \mathbf{C}$ \\
\hline $\mathbf{2 0}$ & & \\
\hline $\mathbf{4 0}$ & $\approx 1 \mathrm{~h}$ & $\approx 30 \mathrm{~min}$ \\
\hline & $\approx 2 \mathrm{~h}$ & $\approx 1 \mathrm{~h}$ \\
\hline
\end{tabular}

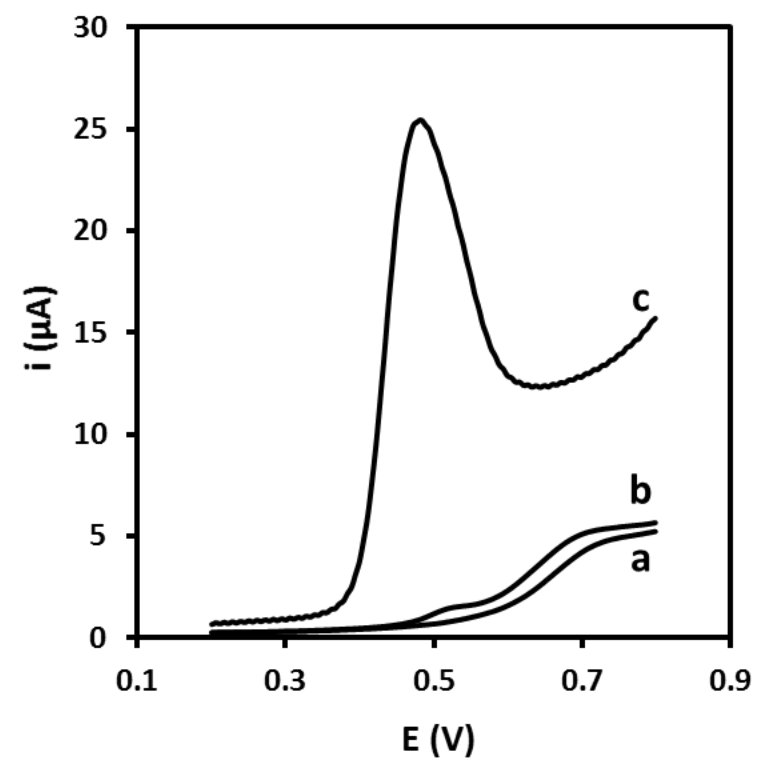

Fig. S7. LSVs recorded in $10 \mu \mathrm{L}$ of $0.1 \mathrm{M} \mathrm{PB}$ pH 7.0 after preconcentration of $40 \mu \mathrm{L}$ of: (a) tap water and tap water spiked with DCF to obtain final concentrations of (b) 0.5 and (c) 50 $\mu \mathrm{M}$. Scan rate: $100 \mathrm{mV} \mathrm{s}^{-1}$. 
Table S2. Comparison of the analytical performance of this electroanalytical platform with others recently reported in the literature for DCF determination

\begin{tabular}{|c|c|c|c|c|c|}
\hline Electrode & Construction & Detection & $\begin{array}{l}\text { Linear range } \\
(\mu \mathrm{M})\end{array}$ & $\begin{array}{l}\text { LOD } \\
(\mu \mathrm{M})\end{array}$ & Ref. \\
\hline Carbon ink & Paper-based platform & LSV & $\begin{array}{l}0.10-5.0 \\
5.0-100\end{array}$ & 0.07 & This work \\
\hline $\begin{array}{l}\text { Cylindrical } \\
\text { graphite }\end{array}$ & Thread-based device & MPA & $10-320$ & 4.7 & [1] \\
\hline $\mathrm{CPE}$ & $\mathrm{MWCNTs} / \mathrm{MgFe}_{2} \mathrm{O}_{4}$ & DPV & $0.100-580$ & 0.06 & [2] \\
\hline $\mathrm{CPE}$ & NiO-SWCNTs/DDPM & SWV & $0.04-1200$ & 0.008 & [3] \\
\hline CPE & IL/MWCNTs & SWV & $0.3-750$ & 0.09 & [4] \\
\hline GCE & $\mathrm{GO}-\mathrm{COOH}$ & LSV & $1.2-400$ & 0.09 & [5] \\
\hline GCE & AuNP/MWCNT & SWV & $0.03-200$ & 0.02 & [6] \\
\hline GCE & MWCNTs/CTS-Cu & SWV & $0.3-200$ & 0.021 & [7] \\
\hline $\begin{array}{l}\text { Carbon } \\
\text { ceramic }\end{array}$ & MWCNT-IL & DPV & $0.05-50$ & 0.018 & [8] \\
\hline $\begin{array}{l}\text { MWCNTs } \\
\text { paste }\end{array}$ & CoHCF/IL & DPV & $1.0-100.0$ & 0.3 & [9] \\
\hline $\begin{array}{l}\text { Graphite } \\
\text { pencil }\end{array}$ & MWCNTs-modified & DPV & $0.047-12.95$ & 0.017 & {$[10]$} \\
\hline $\begin{array}{l}\text { Graphite } \\
\text { pencil }\end{array}$ & Doped polypyrrole film & Potentiometry & $310-11000$ & 190 & {$[11]$} \\
\hline Gold & $\begin{array}{l}\text { Aptamer/NiHCF/PtNPs } \\
\text { /PEI/CNTs }\end{array}$ & EIS & $0.010-0.200$ & 0.0027 & {$[12]$} \\
\hline
\end{tabular}

LSV: linear sweep voltammetry; MPA: multiple pulse amperometry; DPV: differential pulse voltammetry; SWV: square wave voltammetry; EIS: electrochemical impedance spectroscopy; CPE: carbon paste electrode; GCE: glassy carbon electrode; MWCNTs: multi-walled carbon nanotubes; SWCNTs: single-walled carbon nanotubes; CNTs: carbon nanotubes; DDPM: 2,4-dimethyl-N/-[1-(2,3-dihydroxy phenyl)methylidene]aniline; GO-COOH: carboxyl-functionalized graphene oxide; AuNP: gold nanoparticles; CTS-Cu: chitosan-copper complex; CoHCF: cobalt hexacyanoferrate; IL: ionic liquid; NiHCF: nickel hexacyanoferrate; PtNPs: platinum nanoparticles; PEI: polyethyleneimine. 
Table S3. Overview of some general parameters of the tap water used as real sample (data provided by the water supplying company of Oviedo, Aqualia [13]).

\begin{tabular}{|c|c|c|}
\hline Parameter & Units & Data \\
\hline Arsenic & $\mu \mathrm{g} / \mathrm{L}$ & $<7.5$ \\
\hline Cadmium & $\mu \mathrm{g} / \mathrm{L}$ & $<1.50$ \\
\hline Copper & $\mu \mathrm{g} / \mathrm{L}$ & $<0.0150$ \\
\hline Chromium & $\mu \mathrm{g} / \mathrm{L}$ & $<5.0$ \\
\hline PAHs & $\mu \mathrm{g} / \mathrm{L}$ & $<0.025$ \\
\hline Mercury & $\mu \mathrm{g} / \mathrm{L}$ & $<0.5$ \\
\hline Nickel & $\mu \mathrm{g} / \mathrm{L}$ & $<3.00$ \\
\hline Lead & $\mu \mathrm{g} / \mathrm{L}$ & $<6.0$ \\
\hline Cobalt & $\mu \mathrm{g} / \mathrm{L}$ & $<5.00$ \\
\hline Silver & $\mu \mathrm{g} / \mathrm{L}$ & $<10$ \\
\hline Chlorides & $\mathrm{mg} / \mathrm{L}$ & $2.84 \pm 0.47$ \\
\hline Iron & $\mu \mathrm{g} / \mathrm{L}$ & $<30.0$ \\
\hline Sodium & $\mathrm{mg} / \mathrm{L}$ & $<5.0$ \\
\hline Sulphates & $\mathrm{mg} / \mathrm{L}$ & $6.58 \pm 0.52$ \\
\hline Calcium & $\mathrm{mg} / \mathrm{L}$ & $48.1 \pm 9.6$ \\
\hline Phosphates & $\mathrm{mg} / \mathrm{L}$ & $<1.0$ \\
\hline Potassium & $\mathrm{mg} / \mathrm{L}$ & $<5.0$ \\
\hline Silicon & $\mathrm{mg} / \mathrm{L}$ & $<5.35$ \\
\hline Magnesium & $\mathrm{mg} / \mathrm{L}$ & $<5.0$ \\
\hline $\mathrm{CO}_{2}$ & $\mathrm{mg} / \mathrm{L}$ & 1.8 \\
\hline Conductivity & $\mu \mathrm{S} / \mathrm{cm}$ & $233 \pm 22\left(20^{\circ} \mathrm{C}\right)$ \\
\hline Turbidity & UNF & $<0.50$ \\
\hline TOC & $\mathrm{mg} / \mathrm{L}$ & $1.60 \pm 0.64$ \\
\hline $\mathrm{pH}$ & & $8.11 \pm 0.21\left(25^{0} \mathrm{C}\right)$ \\
\hline Total hardness & $\mathrm{mg} / \mathrm{L} \mathrm{CaCO}_{3}$ & 130.1 \\
\hline
\end{tabular}




\section{References}

[1] D. Agustini, M.F. Bergamini, L.H. Marcolino-Junior, Low cost microfluidic device based on cotton threads for electroanalytical application, Lab Chip. 16 (2016) 345-352. doi:10.1039/c5lc01348h.

[2] F. Basiri, M. Taei, Application of spinel-structured MgFe2O4 nanoparticles for simultaneous electrochemical determination diclofenac and morphine, Microchim. Acta. 184 (2017) 155-162. doi:10.1007/s00604-016-1995-0.

[3] Y. Akbarian, M. Shabani-Nooshabadi, H. Karimi-Maleh, Fabrication of a new electrocatalytic sensor for determination of diclofenac, morphine and mefenamic acid using synergic effect of NiO-SWCNT and 2, 4-dimethyl-N/-[1- (2, 3-dihydroxy phenyl) methylidene] aniline, Sensors Actuators, B Chem. 273 (2018) 228-233. doi:10.1016/j.snb.2018.06.049.

[4] M. Goodarzian, M.A. Khalilzade, F. Karimi, V. Kumar Gupta, M. Keyvanfard, H. Bagheri, M. Fouladgar, Square wave voltammetric determination of diclofenac in liquid phase using a novel ionic liquid multiwall carbon nanotubes paste electrode, $\mathrm{J}$. Mol. Liq. 197 (2014) 114-119. doi:10.1016/j.molliq.2014.04.037.

[5] C. Karuppiah, S. Cheemalapati, S.M. Chen, S. Palanisamy, Carboxyl-functionalized graphene oxide-modified electrode for the electrochemical determination of nonsteroidal anti-inflammatory drug diclofenac, Ionics. 21 (2015) 231-238. doi:10.1007/s11581-014-1161-9.

[6] A. Afkhami, A. Bahiraei, T. Madrakian, Gold nanoparticle/multi-walled carbon nanotube modified glassy carbon electrode as a sensitive voltammetric sensor for the determination of diclofenac sodium, Mater. Sci. Eng. C. 59 (2016) 168-176. doi:10.1016/j.msec.2015.09.097.

[7] M. Shalauddin, S. Akhter, S. Bagheri, M.S. Abd Karim, N. Adib Kadri, W.J. Basirun, Immobilized copper ions on MWCNTS-Chitosan thin film: Enhanced amperometric sensor for electrochemical determination of diclofenac sodium in aqueous solution, Int. J. Hydrogen Energy. 42 (2017) 19951-19960. doi:10.1016/j.ijhydene.2017.06.163.

[8] K. Sarhangzadeh, A.A. Khatami, M. Jabbari, S. Bahari, Simultaneous determination of diclofenac and indomethacin using a sensitive electrochemical sensor based on multiwalled carbon nanotube and ionic liquid nanocomposite, J. Appl. Electrochem. 43 (2013) 1217-1224. doi:10.1007/s10800-013-0609-3.

[9] S. Damiri, Y.M. Oskoei, M. Fouladgar, Highly sensitive voltammetric and impedimetric sensor based on an ionic liquid/cobalt hexacyanoferrate nanoparticle 
modified multi-walled carbon nanotubes electrode for diclofenac analysis, J. Exp. Nanosci. 11 (2016) 1384-1401. doi:10.1080/17458080.2016.1233581.

[10] G.P. Fard, E. Alipour, R.E. Ali Sabzi, Modification of a disposable pencil graphite electrode with multiwalled carbon nanotubes: application to electrochemical determination of diclofenac sodium in some pharmaceutical and biological samples, Anal. Methods. 8 (2016) 3966-3974. doi:10.1039/C6AY00441E.

[11] M.C. Oliveira, E.H. Bindewald, L.H. Marcolino, M.F. Bergamini, Potentiometric determination of diclofenac using an ion-selective electrode prepared from polypyrrole films, J. Electroanal. Chem. 732 (2014) 11-16. doi:10.1016/j.jelechem.2014.08.006.

[12] H. Derikvand, M. Roushani, A.R. Abbasi, Z. Derikvand, A. Azadbakht, Design of folding-based impedimetric aptasensor for determination of the nonsteroidal antiinflammatory drug, Anal. Biochem. 513 (2016) 77-86. doi:10.1016/j.ab.2016.06.013.

[13] https://www.aqualia.com/es/web/aqualia-oviedo/calidad-y-medioambiente/analisis-deagua (Last accessed May 2018). 